BONPLANDIA 15(1-2): 5-45. 2006

\title{
LAS ESPECIES ARGENTINAS Y DE PAÍSES VECINOS DE SIDA SECC. NELAVAGA (MALVACEAE, MALVEAE)
}

\author{
ANTONIO KRAPOVICKAS ${ }^{1}$
}

\begin{abstract}
Summary: Krapovickas, A. 2006. The species from Argentina and the neighboring countries of Sida sect. Nelavaga (Malvaceae, Malveae). Bonplandia 15(1-2): 5-45. ISSN: 0524-0476.

The species of Sida section Nelavaga Borss. Waalk. from Argentina, Bolivia, Brazil and Paraguay are revised. Six new species are described: S. Cabreriana, S. pindapoyensis, S. Schininii, S. Schumanniana, S. vagans and S. Waltoniana. A key is provided to distinguish the 24 species from the area. A table with chromosome counts is included.
\end{abstract}

Key words: Sida, Nelavaga, Malvaceae, Argentina, Bolivia, Brasil, Paraguay.

Resumen: Krapovickas, A. 2006. Las especies argentinas y de países vecinos de Sida secc. Nelavaga (Malvaceae, Malveae). Bonplandia 15(1-2): 5-45. ISSN: 0524-0476.

Se revisa la sección Nelavaga Borss. Waalk. del género Sida para Argentina, Bolivia, Brasil y Paraguay. Se tratan 24 especies de las cuales seis son nuevas: S. Cabreriana, S. pindapoyensis, S. Schininii, S. Schumanniana, S. vagans y S. Waltoniana. Se incluye una clave y una tabla con recuentos cromosómicos.

Palabras clave: Sida, Nelavaga, Malvaceae, Argentina, Bolivia, Brasil, Paraguay.

\section{Introducción}

La sección Nelavaga del género Sida L. fue creada por Borssum Waalkes en 1966 para un grupo de especies de Malasia. Utilizó el nombre vernáculo «néla-vága» bajo el cual van Rheede (1690) describe e ilustra (Fig.1) una planta que Borssum Waalkes atribuye a $S$. cordata (Burm.f.) Borss. Waalk.

Esta sección abarca especies con 5 carpelos, hojas cordadas, agudas, con frecuencia cáliz con el margen de los lóbulos verde oscuro y los mericarpos, cuando aristados, con aristas con pelos antrorsos. La mayoría de sus especies con mericarpos trígonos tienen $\mathrm{x}=8$ cromosomas. En cambio S. Luschnathiana Steud. $(2 n=28)$ y S. Schininii Krapov. $(2 n=14)$, con mericarpos redondos tienen $\mathrm{x}=7$ (Tabla 1 ).

\section{Distribución geográfica}

En Malasia viven cuatro especies: Sida cordata, S. elongata Blume, S. javensis Cav. y $S$. mysorensis Wight \& Arn. (Borssum Waalkes, 1966). Este autor cita también a $S$. glutinosa Comm. ex Cav., pero la ubica en la sección Sida, a pesar de tener caracteres correspondientes a la sección Nelavaga (Fuertes Aguilar, 1995).

${ }^{1}$ Instituto de Botánica del Nordeste, Casilla de Correo 209, 3400 Corrientes, Argentina. 


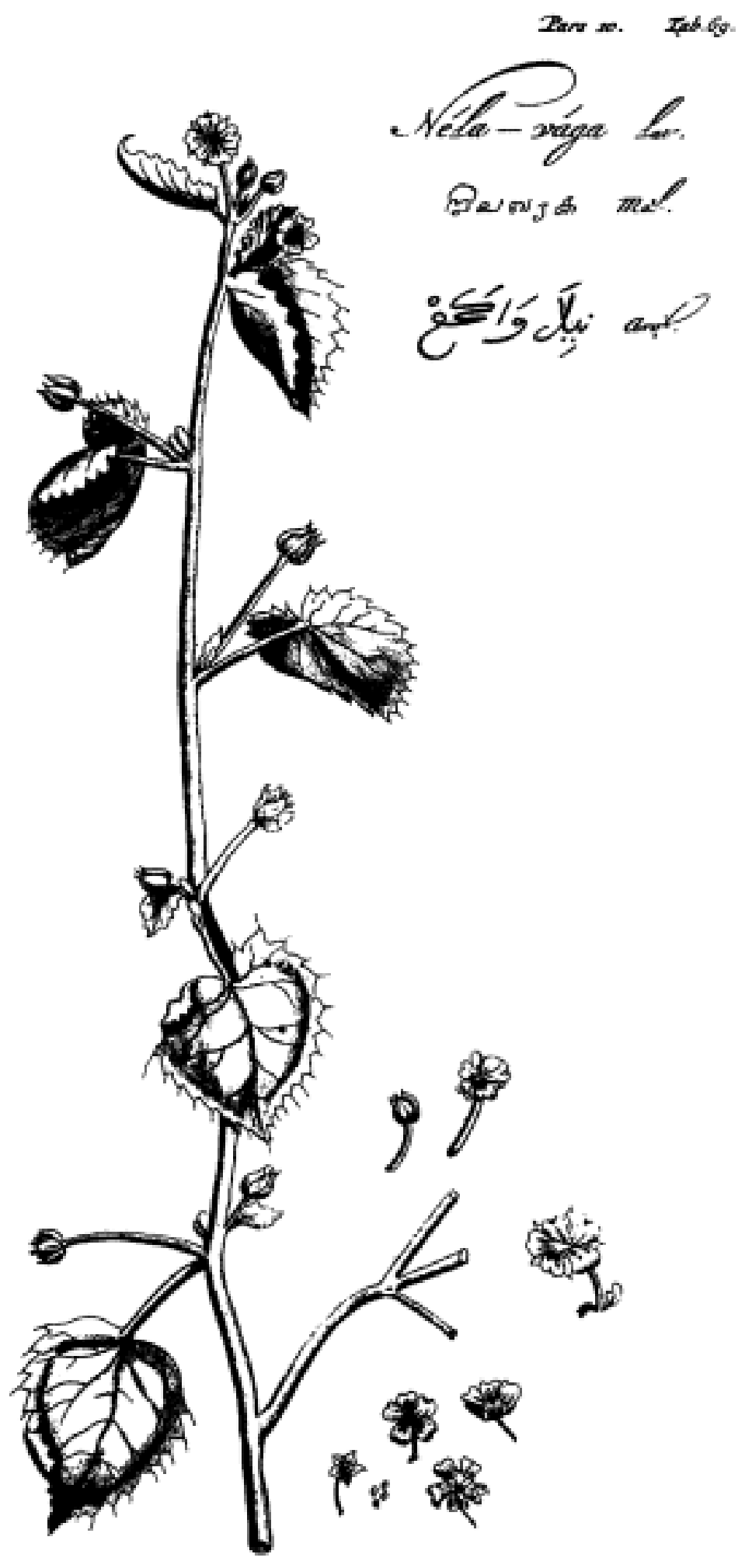

Fig. 1. Néla-vága Rheede, Hort. malab. vol. 10: tab. 69. 1690. 
Tabla 1. Número de cromosomas (2n) de Sida secc. Nelavaga.

\begin{tabular}{|c|c|c|c|c|}
\hline & Especie & $2 n$ & Procedencia & Bibliografía \\
\hline & S. Cabreriana & 16 & K. 6701 AR, Ju, Las Lajitas & Krapovickas (1957, sub S. veronicifolia) \\
\hline & S. dictyocarpa & 16 & K. 7973 AR, Cd, La Calera & Krapovickas (1969) \\
\hline & $"$ & 16 & K. 10505 BR, Mg, Rio das Velhas & Krapovickas (1969) \\
\hline & S. glutinosa & 16 & K. 8289 HO, El Zamorano & Krapovickas (1969) \\
\hline & $"$ & 16 & K. \& al. 15559 VE, Maracay & Fernández (1974) \\
\hline & S. Jussieana & 16 & G. \& al. 10238 BR, Go, rio Maranhao & Krapovickas (1969) \\
\hline & $"$ & 16 & K \& S. 7982 AR, Sa, Campo Durán & Krapovickas (1969) \\
\hline & S. nemorensis & 16 & M. 227 AR, Ms, Loreto & Krapovickas (1957, sub S. melanocaulon) \\
\hline & S. Schininii & 14 & K.32250 BO, Sc, S.Ignacio & Fernández (1981, sub S. Martiana) \\
\hline O & S. Luschnathiana & 28 & G. \& al. 10151 BR, Go, Caldas Novas & \\
\hline \multirow[t]{6}{*}{ O } & S. pindapoyensis & 32 & K. 7933 AR, Ms. Ayo.Pindapoy & \\
\hline & $"$ & 32 & K. 7935 & Fernández \& al. (2003, sub S. rufescens) \\
\hline & S. urens & 32 & & Skovsted (1935) \\
\hline & $"$ & 32 & C \& T. 2325 PE, Ju, S. Ramón & Krapovickas (1969) \\
\hline & $"$ & 32 & Berrie s.n. SL, Freetown & Ugborogho (1975) \\
\hline & $"$ & 32 & B \& E. 504 AR, Ms, S. Ignacio & Krapovickas (1957) \\
\hline O & $"$ & 32 & K. 7992 AR, Sa, Campo Durán & \\
\hline O & $"$ & 32 & K. \& al. 28464 AR, Sa, La Caldera & \\
\hline
\end{tabular}

O recuento nuevo, AR:Argentina, BO: Bolivia, BR: Brasil, HO: Honduras, PA: Paraguay, PE: Perú, SL: Sierra Leona (África), VE: Venezuela, Cd: Córdoba, Go: Goyás, Ju: Jujuy, Mg: Minas Gerais, Ms: Misiones, Sa: Salta, Sc: Santa Cruz, B\&E: Berti \& Escalante, C: Constance, C\&T: Constance \& Tovar, G: Gregory, K: Krapovickas, K\&P: Krapovickas \& Pietrarelli, K\&S: Krapovickas \& Schinini, M: Montes.

Para el sur de la India, Sivarajan \& Pradeep (1996) mencionan Sida beddomei Jacob, S. cordata, S. elongata, S. mysorensis y $S$. repens Cav.

Para África se han mencionado Sida cordata (sub S. veronicifolia Lam.) y S. urens L. (Meeuse, 1961; Hauman, 1963).

En América del Norte y en Centroamérica viven 11 especies: Sida alamosana S.Wats., S. anodifolia Fryxell, S. cordata, S. glabra Mill., S. glutinosa, S. Jussieana DC., S. Martiana A.St.-Hil., S. michoacana Fryxell, S. monticola Fryxell, S. nesogena I.M.Johnst., S. repens y S. urens (Fryxell, 1985, 1987).

En las Antillas habitan Sida glabra, S. glutinosa, S. hederifolia Cav. y S. urens.

En Colombia viven Sida Eugeniae Fuertes, S. glabra, S. glutinosa, S. Jussieana, S. Martiana y S. urens (Fuertes Aguilar, 1995)

Para Ecuador se han citado Sida repens y $S$. urens (Fryxell, 1992).

En Perú viven Sida repens (sub $S$. veronicifolia), S. urens (Macbride, 1956) y $S$. rufescens A.St.-Hil.

En Bolivia viven 14 especies: Sida Cabreriana Krapov., S. dictyocarpa K.Schum., S. Emilei Hochr., S. esperanzae R.E.Fr., S. gracilipes Rusby, S. Jussieana, S. Luschnathiana, S. nemorensis Mart. ex Colla, S. rufescens, $S$. rupicola Hassl., S. Schininii, S. Schumanniana Krapov., S. urens y $S$. vagans. Las únicas endémicas son $S$. gracilipes de los valles intermontanos semiáridos y $S$. vagans de las llanuras del norte de Santa Cruz.

En Brasil crecen 16 especies: Sida caudata A.St.-Hil. \& Naudin, S. cearensis Ulbr., S. chapadensis K.Schum., S. Emilei, S. glutinosa, S. goyazensis K. Schum.,S. Jussieana, S. laciniata Bovini, S. Luschnathiana, S. Martiana, S. nemorensis, S. rufescens, S. rupicola, S. 
Schininii, S. Schumanniana, S. urens y $S$. Waltoniana Krapov. Las especies exclusivas son: S. caudata, S. cearensis, S. chapadensis, S. goyazensis, S. laciniata, S. Martiana y $S$. Waltoniana.

En Paraguay viven 10 especies: Sida Cabreriana, S. dictyocarpa, S. Emilei, S. esperanzae, S. gracillima Hassl., S. nemorensis, S. rufescens, S. rupicola, S. Schumanniana y $S$. urens. La única especie endémica es $S$. gracillima, que fue coleccionada una sola vez.

En Argentina se han registrado 9 especies: Sida Cabreriana, S. dictyocarpa, S. esperanzae, S. Jussieana, S. nemorensis, S. pindapoyensis Krapov., S. rupicola, S. Schumanniana y $S$. urens. La única especie endémica es $S$. pindapoyensis. En Argentina se encuentra el límite Sur de la sección, a los $33^{\circ}$ de latitud.

En Chile y Uruguay no crecen especies de esta sección.

\section{Sida secc. Nelavaga Borss. Waalk.}

Borssum Waalkes, J. van., Blumea 14(1): 180. 1966. Especie tipo: Sida cordata (Burm.f.) Borss. Waalk. (= Melochia cordata Burm.f.).

Lamarkia Medik., Vorles. Churpfälz. Phys.Öcon. Ges. 4(1): 183. 1788 (nom. rej.). Especie tipo: L. morifolia (Cav.) Medik. [= S. cordata (Burm.f.) Borss.Waalk.].

Nela Vaga Rheede [= Sida radicans Cav. 1785, = S. cordata (Burm.f.) Borss. Waalk. 1966].

\section{Clave para distinguir las especies de Sida secc. Nelavaga}

1. Cáliz acrescente, hojas asimétricas.

12. S. Jussieana DC.

1'. Cáliz no acrescente. Hojas simétricas.

2. Flores en glomérulos axilares. Todas las flores cortamente pediceladas, pedicelos 1-3 mm long.

3. Mericarpos múticos o submúticos.

4. Tallo con pelos glandulares y setas $2 \mathrm{~mm}$ long. Plantas rastreras o apoyantes. Haz con pelos estrellados y pelos simples.

22. S. urens L.

4'. Tallo sin pelos glandulares.

5. Cáliz 8-12 mm long. Pelos glandulares sólo en el cáliz. Tallo y cáliz con setas largas, esparcidas. Planta rastrera.

21. S. Schumanniana Krapov.

5'. Cáliz 5-6 mm long.

6. Tallo, hojas y cáliz con pelos estrellados, abundantes. Planta decumbente.

18. S. rufescens A.St.-Hil.

6'. Tallo, hoja y cáliz con pelos simples. Tubo estaminal glabro. Planta erecta.

13. S. laciniata Bovini

3'. Mericarpos aristados, dorso reticulado. Plantas erectas.

7. Tallo con pelos glandulares, pelos estrellados y setas largas.

16. S. nemorensis Mart. ex Colla

7'. Tallo sin pelos glandulares.

8. Pétalos 6-7 mm long., con la uña pilosa. Aristas breves.

2. S. caudata A.St.-Hil. \& Naudin 
8'. Pétalos 12 mm long., glabros. Aristas $2 \mathrm{~mm}$ long.

6. S. Emilei Hochr.

2'. Flores 1-2 por axila.

9. Flores 1-2 por axila, pedicelos 2-6 mm long. Hojas con pelos estrellados cobrizos en ambas caras, densamente dispuestos. Cáliz de color cobrizo uniforme.

17. S. pindapoyensis Krapov.

9'. Flores axilares solitarias, pedicelos 10-50 mm long., a veces con una ramita breve con flores cortamente pediceladas.

10. Flores solitarias, pedicelos 1-5 cm long.

11. Hojas y tallo adultos glabros a subglabros.

12. Plantas erectas. Tallo sin raíces adventicias.

13. Pecíolo con una línea angosta de pelos estrellados muy pequeños y densos. Mericarpos 3-4 mm long., casi múticos o aristas $4 \mathrm{~mm}$. Follaje negruzco en seco.

3. S. cearensis Ulbr.

13'. Pecíolo glabro. Mericarpos 3 mm más arista 1 mm long. Follaje verde-claro en seco.

11. S. gracillima Hassl.

12'. Planta rastrera. Tallo con raíces adventicias.

23. S. vagans Krapov.

11'. Tallo y hojas pilosos.

14. Tallo con pelos glandulares.

15. Mericarpos redondos.

16. Haz con pelos glandulares pequeños. $2 \mathrm{n}=28$.

14. S. Luschnathiana Steud.

16'. Haz con pelos simples.

17. Haz con pelos 0,5-1 mm long. Mericarpos múticos, con pelos muy pequeños en el ápice.

15. S. Martiana A.St.-Hil.

17'. Haz con pelos simple menores de 0,2 mm. Mericarpos con aristas 0,5 mm long., dorso y ápice pilosos. $2 \mathrm{n}=14$.

20. S. Schininii Krapov.

15'. Mericarpos trígonos, con pelos en la línea de dehiscencia.

18. Mericarpos múticos.

19. Haz con pelos simples 0,5-1 mm long.

19'. Haz con pelos estrellados.

9. S. goyazensis K.Schum.

24. S. Waltoniana Krapov.

18'. Mericarpos aristados. Aristas breves, menores de $1 \mathrm{~mm}$ long.

20. Cáliz 8-11 mm long.

10. S. gracilipes Rusby

20'. Cáliz 4-6 mm long.

21. Uña con pelos. Haz con pelos estrellados. Mericarpos con dorso liso o apenas reticulado. Tubo estaminal con pelos estrellados.

8. S. glutinosa Cav. 
21'. Uña glabra. Haz con pelos simples. Dorso de los mericarpos con retículo marcado. Tubo estaminal con pelos simples.

19. S. rupicola Hassl.

14'. Tallo sin pelos glandulares. Pétalos con uña pilosa. Tubo estaminal glabro. Mericarpos múticos. Tallo con pelos estrellados 0,5-1 mm long.

4. S. chapadensis K. Schum.

10'. Flores solitarias y en la axila ramitas con flores subsésiles.

22. Tallo con pelos glandulares.

23. Pelos glandulares abundantes, a veces setas $2 \mathrm{~mm}$ long. presentes. Haz de la hoja con pelos estrellados pequeños.

7. S. esperanzae R.E.Fr.

23'. Tallo con pelos glandulares esparcidos y setas 2-3 mm long. abundantes. Haz de la hoja con pelos simples adpresos.

5. S. dictyocarpa K.Schum.

22'. Tallo sin pelos glandulares.

24. Cáliz 6-9 mm long. Mericarpos con aristas 1,5-2 mm long. Tallo con pelos estrellados 0,5-1 mm long.

6. S. Emilei Hochr.

24'. Cáliz 5-6 mm long. Mericarpos con aristas 0,2-1,5 mm long. Tallo con pelos estrellados menores de $0,2 \mathrm{~mm}$.

1. S. Cabreriana Krapov.

\section{Sida Cabreriana Krapov., sp. nov.}

Fig. 3

Suffrutex 0,50-1,50 m altus. Caulibus pilis stellatis minutis tomentosis. Lamina ovata acuminata basi cordata, supra et infra pilis stellatis inspersa. Floribus axillaribus, pedicellis usque ad $15 \mathrm{~mm}$ longis, frequens glomeruli presentis. Calyx 5-6 mm longis. Petalis $7 \mathrm{~mm}$ longis. Carpidiis trigonis 3,5 $\mathrm{mm}$ longis, aristis 0,2-1,5 mm longis.

Typus: Argentina, Jujuy, Dep. Palpalá, Cuesta de las Lajitas, 13-V-1998, A. Krapovickas, A. Schinini \& G. Seijo 47394 (holotypus CTES, isotypi CORD, G, JUA, MCNS, NY, SI, TEX).

Subarbusto de 0,50-1,50 m alt. Tallo cubierto de pelos estrellados pequeños a subglabro, puede haber algunos pelos simples 1-2 $\mathrm{mm}$ long. Hojas espiraladas. Estípulas lanceoladas, 4-8 mm long., persistentes, pilosas. Pecíolo en ramas floríferas breve, 5-10 mm long., en hojas basales hasta 35 mm long., uniformemente cubierto de pelos estrellados muy pequeños. Lámina ovada, de base cordada, ápice agudo y margen crenado-aserrado, hasta $8 \mathrm{~cm}$ long. $\times 4 \mathrm{~cm}$ lat. en las hojas basales, en las ramas floríferas mucho más breves, haz con pelos estrellados muy pequeños que dejan ver la superficie de la epidermis, algo mayores sobre los nervios, envés con pelos estrellados algo mayores. Flores axilares con pedicelos hasta $15 \mathrm{~mm}$ long., articulados en el tercio superior, con pelos estrellados muy pequeños; con frecuencia en la axila nace un glomérulo o una ramita florífera con pedicelos muy breves. Cáliz campanulado, 5-6 mm long., cubierto uniformemente de pelos estrellados muy pequeños, lóbulos triangulares, 3-5 mm long. x $3 \mathrm{~mm}$ lat., margen con cilias muy breves. Pétalos $7 \mathrm{~mm}$ long. x $5 \mathrm{~mm}$ lat., amarillos, glabros. Tubo estaminal 2-2,5 mm long., con pelos simples, hialinos. Estilos 5, reflexos. Mericarpos trígonos, 3,5 mm long. x $1 \mathrm{~mm}$ lat., aristas apicales $0,2-1,5 \mathrm{~mm}$ long., caras laterales 

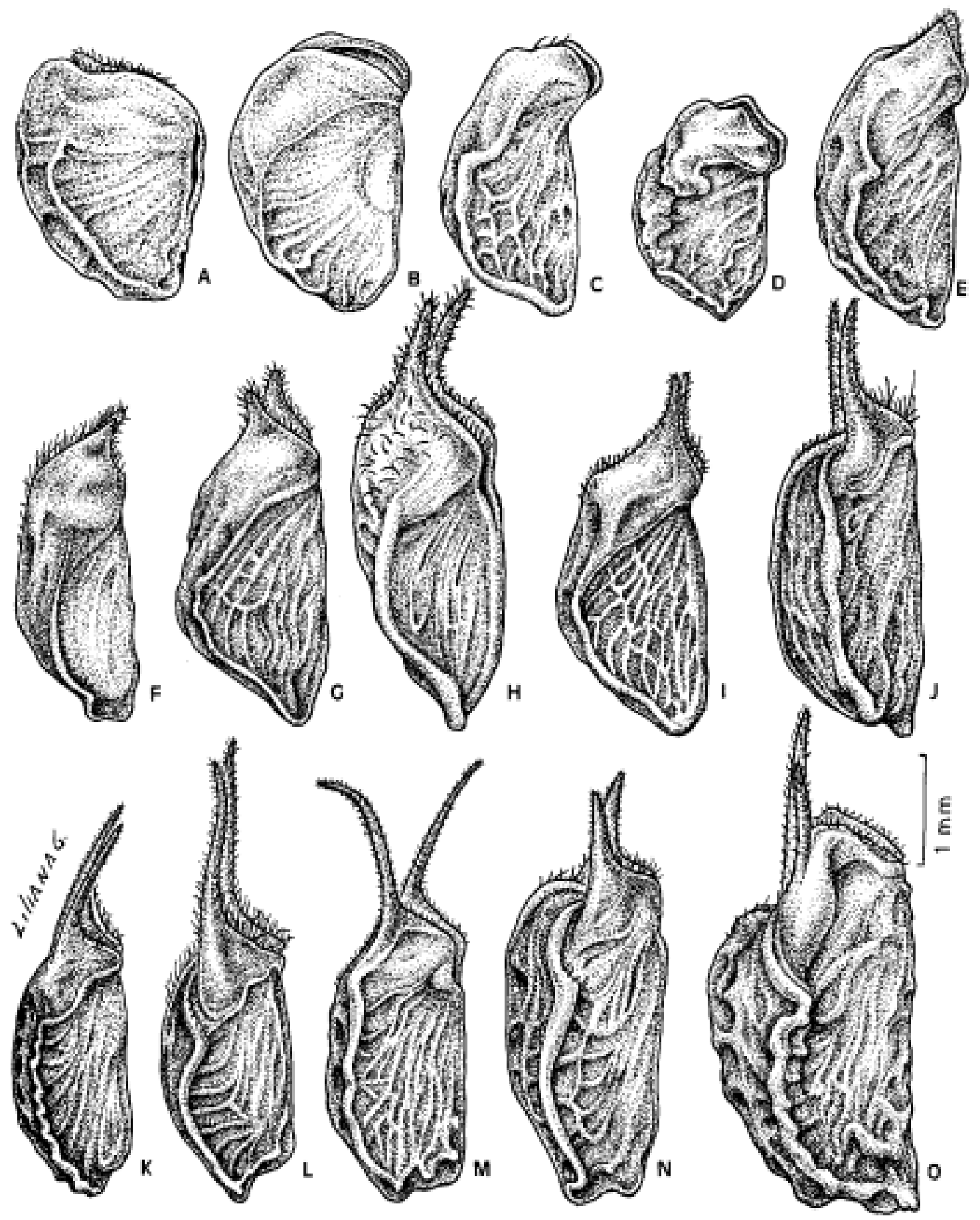

Fig. 2. Mericarpos de Sida secc. Nelavaga. A: S. Martiana (Hensold 2922). B: S. Luschnathiana (Pinto 50-25). C: S. goyazensis (Hatschbach 70809). D: S. rufescens (Krapovickas 40107). E: S. urens (Tressens 5241). F: S. cearensis (Ducke 1332). G: S. caudata (Arbo 3985). H: S. nemorensis (Hassler 10294). I: S. glutinosa (Fernandes 1435). J: S. gracillima (Fiebrig 5173). K: S. dictyocarpa (Krapovickas 46597). L: S. Emilei (Krapovickas 14228). M: S. esperanzae (Krapovickas 18632). N: S. rupicola (Schinini 17852). O: S. gracilipes (Gutiérrez 1542). 
reticuladas, resistentes, con pelos simples hacia el ápice de la cara dorsal y con pelos antrorsos en las aristas.

Distribución geográfica: Vive en el noroeste de Argentina, sudeste de Bolivia y oeste de Paraguay. Frecuente en el interior de bosques, como la Selva tucumano-boliviana o el Chaco serrano, en ambientes más húmedos que los de $S$. esperanzae o $S$. dictyocarpa, especies heliófilas.

Etimología: Nombre dedicado al Dr. Angel Lulio Cabrera (1908-1999) especialista en Compuestas e iniciador de una Flora de la provincia de Jujuy, donde esta especie vive preferentemente.

Paratypi: ARGENTINA. Formosa: Dep. Bermejo, 42 km SE de Laguna Yema, 26-XI-1994, Krapovickas \& Cristóbal 46405 (BAB, CTES, NY, SI, TEX); Dep. Patiño, 24 km SE de Pozo del Tigre, 21-II-1006, Krapovickas \& Cristóbal 46544 (BAB, CTES, TEX); Sargento Leyes, 24III-1992, Fortunato \& al. 3082 (BAB, CTES). Jujuy: Dep. Capital, S.S. de Jujuy, 27-VII-1947, Krapovickas 3512 (CTES, JUA, LIL); Cuesta de Chijra, 22-X-1981, Ahumada \& Rotman 4349 (CTES); camino a El Cucho, 11-VI-1983, Cabrera \& al. 33871 (CTES, LP); Las Lajitas, 5-II1950, Krapovickas \& al. 6701 (LIL). Dep. El Carmen, Las Lajitas, 8-XI-1974, Krapovickas \& al. 26575 (BAB, CTES, JUA, LP, TEX). Dep. Ledesma, Yuto, arroyo Saucelito, 22-VII-1963, Cabrera 15818 (CTES, LP); El Bananal, 10-IX1983, Cabrera 34106 (CTES, SI); Parque Nacional Calilegua, río Aguas Negras, 600-800 m, 11IX-1991, Guaglianone \& al. 2524 (CTES, SI); Dep. San Pedro, 10 km SW de La Mendieta, 13-V1998, Krapovickas \& al. 47417 (CTES, US); 6 Km SW de La Mendieta, 13-V-1998, Krapovickas \& al. 47434 (CTES, LIL, US); Dep. Santa Bárbara, Santa Clara, 14-V-1998, Krapovickas \& al. 47436 (CTES, MCNS); Palma Sola, 8-III-1983, Ahumada 4521 (CTES). Dep. Valle Grande, Valle Grande, 12-V-1972, Cabrera \& Fabris 22684 (CTES, LP). Salta: Dep. Anta, río Dorado, 39 km NE de Las Lajitas, 24-IV-1983, Krapovickas \& Schinini 38646 (CTES). Dep. Chicoana, Quebrada de Escoipe, $16 \mathrm{~km}$ W de Chicoana, $1500 \mathrm{~m}$, 19III-1972, Krapovickas \& al. 22104 (CTES). Dep.
Metán, río Juramento, entre Las Juntas y río de las Piedras, 4-IV-1980, Krapovickas \& Schinini 35736 (CTES, SI); El Galpón, 6-V-1975, Krapovickas \& Cristóbal 28197 (BAB, CTES, MCNS). Dep. Orán, Agua Blanca, 4-VI-1970, Legname \& Cuezzo 7474 (CTES, LIL); San Agustín, 1-IV1951, A. de la Sota 4575 (CTES, LIL); Orán, 19III-1905, Spegazzini s.n. (BAB, CTES). Dep. Rosario de la Frontera, Talayaco, 29-III-1975, Krapovickas \& al. 28014 (CORD, CTES); Dep. San Martín, Coronel Cornejo, 9-XII-1972, Maruñak 584 (CTES); Pocitos, 31-V-1971, Krapovickas \& al. 19414 (CTES). Santiago del Estero: Dep. Choya, Sierra de Guasayán, Quebrada de Maquijata, 570 m, 11-VI-1982, Hunziker 24348 (CORD, CTES). Dep. Guasayán, Sierra de Guasayán, ruta 64, 10-V-1981, Krapovickas \& al. 37424 (CTES, IPA). Tucumán: Dep. Graneros, La Cocha, dique San Ignacio, 10-II-1964, Krapovickas \& Cristóbal 11271 (CTES). Dep. Tafí, Ruta 9, Reserva Forestal, cerca del Cadillal, 1-I-1969, Krapovickas \& Cristóbal 14517 (CTES). BOLIVIA. Chuquisaca: Prov. Sud Cinti, El Palmar, Finca La Redonda, 1000 m, 31-V-1995, Holst \& al. 4921 (CTES, USZ). Santa Cruz: Santa Cruz de la Sierra, 5-IV-1979, Krapovickas \& Schinini 34638 (CTES, LPB, USZ); Santa Cruz de la Sierra, 12-IV-1980, Krapovickas \& Schinini 36119 (CTES, LPB, MO, USZ); El Pari, 440 m, 10-IV1946, Peredo s.n. (CTES, LIL); Prov. Chiquitos, Roboré, 24-IV-1980, Krapovickas \& Schinini 36497 (CTES, LPB); Prov. Cordillera, Charagua, 16-IX-1982, Cabrera \& Gutiérrez 33621 (CTES, SI); Prov. Cordillera, Parque Nacional Kaa-Iya del Gran Chaco, 320 m, 16-VII-1998, Fuentes \& Navarro 2596 (CTES, USZ); Prov. Ñuflo de Chávez, 30 km S de Concepción, Krapovickas \& Schinini 32098 (CTES); Prov. Velasco, San Juancito, 27 $\mathrm{km} \mathrm{N}$ de San Ignacio, $400 \mathrm{~m}, 1-\mathrm{V}-1986$, Seidel \& Beck 339 (CTES, LPB); 20 km E de San Ignacio, 6-V-1977, Krapovickas \& Schinini 32485 (CTES, F, SI). Tarija: $80 \mathrm{~km} \mathrm{~S}$ de Boyuibe, $300 \mathrm{~m}$, Sánchez 6 (CTES, USZ); Prov. Gran Chaco, Villa Montes, 6-V-1983, Krapovickas \& Schinini 39201 (CTES); Algarrobal, 20 km E de Villa Montes, 27V-1971, Krapovickas \& al. 19342 (CTES); Ipa, 30 km N de Villa Montes, 3-VI-1971, Krapovickas \& al. 19461 (CTES, LPB); Ipa, Quebrada de Thainguate, 3-VI-1971, Krapovickas \& al. 19475 (CTES); 29 Km N de Villa Montes, 550 m, 27-IX-1985, Beck 11650 (CTES, LPB); Campo Pajoso, 15 km N de 
A. Krapovickas, Sida secc. Nelavaga (Malvaceae, Malveae)

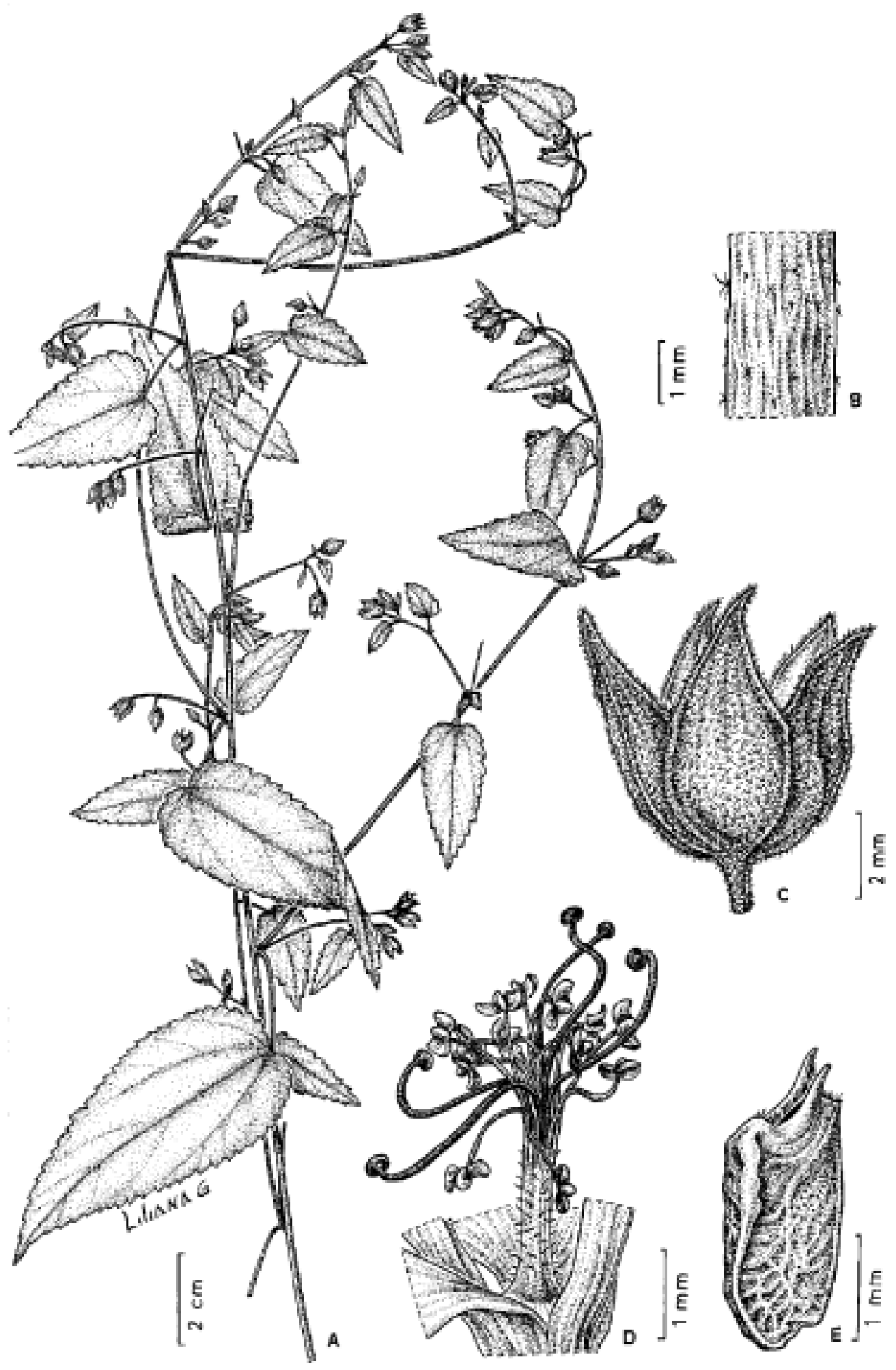

Fig. 3. Sida Cabreriana. A: rama. B: tallo. C: cáliz. D: androceo y gineceo. E: mericarpo (A, Krapovickas 19016. BE, Krapovickas 47394). 
Yacuiba, 630 m, 23-IX-1985, Beck \& al. 11472 (CTES, LPB); Prov. O’Connor, Entre Ríos, 1450 m, 20-V-1971, Krapovickas \& al. 19020 (CTES, LPB, MO, SI, USZ); Entre Ríos, 29-IV-1983, Krapovickas \& Schinini 38851 (C, CTES, LPB, UC); 15 km E de Entre Ríos, 22-V-1971, Krapovickas \& al. 19128 (CTES, LPB, MO, SI, TEX, USZ); Cañadas, 980 m, 25-V-1971, Krapovickas \& al. 19198 (CTES, LPB, MO); San Simón, 23-V1971, Krapovickas \& al. 19246 (CTES). PARAGUAY. Alto Paraguay: Cerro Cabrera, $19^{\circ} 40^{\prime} \mathrm{N}$, 614'' W, 29-X-1992, Fortunato \& al. 3676 (BAB, CTES, G); P. N. Defensores del Chaco, 8X-1998, Quintana \& al. 662 (CTES, PY). Boquerón: Mariscal Estigarribia, 12-XII-1992, Krapovickas \& Cristóbal 44380 (CTES); Col. Neuland, 13-IX-1990, Vanni \& al. 2076 (CTES, FCQ).

Obs. Los mericarpos de S. Cabreriana tienen aristas de longitud variable y también submúticos, en general son más breves que las de $S$. dictyocarpa y $S$. esperanzae, que son sus especies más afines.

En una población de unos 20 individuos coleccionada en ARGENTINA. Salta: Dep. Chicoana, Chicoana, Los Los, 7-V-1975, Krapovickas \& al. 28259, la mitad tienen mericarpos aristados: 28259A (CTES, BAB, CORD, G, K, LPB, MCNS, MO, NY, SI, TEX) y la otra mitad mericarpos múticos o submúticos: 28295B (CTES, BAB, CORD, G, K, LPB, MCNS, MO, NY, SI, TEX).

Material con mericarpos submúticos: ARGENTINA. Jujuy: Dep. Santa Bárbara, 7 km NE de Aguas Blancas, 14-V-1998, Krapovickas \& al. 47473 (CTES, JUA, SI). Salta: Dep. Capital, Cerro San Bernardo, 16-III-1977, Krapovickas \& Schinini 30207 (CTES); Salta, Parque Industrial, 1300 m, 2-VI-1982, Novara 2724 (MNCS); Sierras de Vélez, 1400 m, 29-II-2000, Tolaba 2419 (MCNS); id., 10-III-2000, Tolaba 2438 (MCNS). Dep. Cerrillos, Cerrillos, 24-VII-1947, Krapovickas 3504 (CTES, MCNS); INTA-Cerrillos, 30IV-1963, Ratier de Colina 355 (MCNS); Dep. El Carmen, entre Los Cedros y Abra de Santa Laura, 1600 m, 26-II-2000, Tolaba 2404 (CTES, MCNS); Perico, 11-V-1975, Krapovickas \& al. 28505 (CTES, SI); Dep. San Martín, Pocitos, 31-V-1971, Krapovickas \& al. 19420 (CTES). Tucumán: El Cadillal, Jardín de las Américas, 27-III-1975,
Krapovickas \& al. 27859 (CTES). BOLIVIA: Tarija, Dep. O'Connor, Berety, 1240 m, 24-V1971, Krapovickas \& al. 19166 (CTES); Bajada de San Simón, 22-V-1971, Krapovickas \& al. 19132 (CTES, LPB, MO); Entre Ríos, 1450 m, 20V-1971, Krapovickas \& al. 19016 (CTES, LPB).

\section{Sida caudata A.St.-Hil. \& Naudin}

Fig. 2 G

Saint Hilaire, A. \& Ch. Naudin, Ann. Sci. Nat. Bot. ser. 2, 18: 52. 1842. "Prov. Minas Geraes.Herb. Mus. Paris". Typus: "Brasil (Minas Geraes), 126, P. Claussen, 1838” (holotypus P! foto F 35534!).

Sida tomentella Miq., Linnaea 22: 553. 1849. “I 16”. Typus: Brasil. Minas Gerais: Caldas, Regnell I 16 (holotypus U, isotypi BR!, P! foto F 35547!, US!).

Planta perenne, erecta, 1,70-2 m alt. Tallo cubierto de pelos estrellados pequeños, más o menos abundantes y a veces también pelos simples 1-2 mm long., esparcidos. Estípulas lineares, 5-8 mm long. pilosas. Pecíolo por lo común 1-2 cm long. pero en hojas basales hasta $4 \mathrm{~cm}$ long., tomento similar al del tallo. Lámina oval-oblonga, base levemente cordada a horizontal, ápice acuminado, margen crenado-aserrado, en hojas adultas 6-9 cm long. x 3-4 cm lat., ambas caras cubiertas de pelos estrellados pequeños. Flores subacaules en glomérulos axilares. Cáliz cubierto de pelos estrellados, más o menos uniformes, hirsutos, como en el resto de la planta; cara interna con pelos simples en la línea media de los lóbulos. Pétalos 6-7 mm long. x 4-5 mm lat., uña con pelos. Tubo estaminal con pelos simples hialinos. Ovario con 5 carpelos. Mericarpos trígonos, 2,5-3 mm long., brevemente aristados, con pocos pelos simples, pequeños, antrorsos en el ápice.

Distribución geográfica: Vive en el Sudeste de Brasil, desde Minas Gerais hasta Paraná, principalmente en matorrales arbustivos.

Nombre vernáculo: “vassoura” (Heringer 5658). 
Material adicional estudiado: BRASIL. Minas Gerais: Caldas, 1845, Widgren 478 (BR); Pouso Alegre, 23-VII-1969, Carauta 907 (CTES, GUA); Jequitibá, 16-VII-1957, Heringer 5658 (CTES, HB); Bandeira do Sul, 20-I-1980, Krapovickas \& Cristóbal 35398 (CTES); Serra do Ouro Branco, 1000 m, 12-V-1990, Arbo \& al. 3985 (CTES, SPF). Paraná: Mun. Campo Largo, Serra S. Luis, 1150 m, 4-IV-1965, Hatschbach 12514 (CTES, MBM), Mun. Ponta Grossa, Parque Vila Velha, 24-II-1967, Hatschbach 16052 (CTES, MBM). Río de Janeiro: Engenheiro Passos, 700 m, 17VIII-1987, Pineschi 244 (CTES, GUA); Petropolis, Correios, 25-III-1870, Glaziou 3872 (P). São

Paulo: Villa Franca, I-1834, Riedel 2328 (P); São Paulo, Cidade Jardim, 20-III-1946, Hoehne s.n. (CTES, SPF).

Obs. En P, el ejemplar Regnell I 16, Caldas 18-IV-1874, consta de dos plantas, la de la derecha (foto F 35547) es Sida tomentella Miq. [= S. caudata], con cáliz $8 \mathrm{~mm}$ long. cubierto de pelos estrellados más o menos uniformes, hirtos, pero no es tipo por que la fecha de colección es posterior a la de su publicación (1849). El ejemplar de la izquierda (foto F 35546) es el holotipo de $S$. tomentella var. brevicalyx K. Schum. $[=S$. nemorensis], con cáliz $5 \mathrm{~mm}$ long., con pelos glandulares pequeños muy ralos y pelos simples largos en los 5 nervios principales y en el margen de los lóbulos.

\section{Sida cearensis Ulbr.}

Fig. 2 F

Ulbrich, E., Notizbl. 6: 322-324. 1915. Typus. Brasil. Ceará: "in der Serra de Baturité, an Wegrändern bey Guaramisanga, 500 m”, oktober 1910, Ule $9065 \mathrm{~B} \dagger$, foto F 9374! (lectotypus, aquí designado G!, isotypus $\mathrm{K}$ !).

Subarbusto $1 \mathrm{~m}$ alt., ramas apoyantes. Tallo en las partes muy jóvenes con algunos pelos estrellados, el resto glabro. Estípulas subuladas, 2-3 mm long., con algunos pelos estrellados en el extremo de las ramas, en el resto glabras. Pecíolo 1-4 cm long., glabro excepto una línea longitudinal de pelos bre- ves simples, blanquecinos, estrellados hacia el ápice. Lámina hasta $7 \mathrm{~cm}$ long. x 3-5 cm lat., ovada, base cordada, ápice agudo, margen crenado-aserrado, glabra, en hojas jóvenes con pelos simples muy pequeños, esparcidos. Flores axilares, solitarias. Pedicelo 10-35 mm long., articulado en el tercio superior, glabro. Cáliz campanulado, 7 mm long., lóbulos triangulares, $3 \mathrm{~mm}$ long. x $3 \mathrm{~mm}$ lat., agudos, glabros, márgenes más oscuros y con pelos pequeños simples y algunos estrellados, cara interna de los lóbulos pilosa. Corola amarilla, pétalos $7 \mathrm{~mm}$ long. x $5 \mathrm{~mm}$ lat., uña pilosa. Tubo estaminal 2,5 mm long., con pelos simples hialinos. Ovario 5-carpelar. Mericarpos trígonos, 2,5-4 mm long. x $1 \mathrm{~mm}$ lat., aristas 0,2-2 mm long., caras laterales reticuladas, cara dorsal casi lisa, frágil, ápice y aristas con pelos antrorsos.

Distribución geográfica: Vive en el Nordeste de Brasil, donde fue coleccionada en los estados de Bahía, Ceará y Pará.

Material estudiado: BRASIL. Bahía: Estrada Pedra do Cavalo, Cachoeira, Vale dos rios Paraguaçú e Jacuípe, $12^{\circ} 32^{\prime} \mathrm{S} 39^{\circ} 05^{\prime} \mathrm{W}$, IX-1980, G Pedra do Cavalo 689 (ALCB, CTES). Ceará: Guaramisanga, 417'S 38 56’ W, 18-VII-1908, Ducke 1332 (MG); serra de Maranguape, 24-XI1955, Lima 55-2401 (CTES, IPA). Pará: rio Vermelho, região de Tocantins [ $49^{\circ} 10^{\prime}$ 'W $4^{\circ} 50^{\prime}$ 'S], 12-V-1951, Fróes 27056 (CTES, IAN).

Obs. El ejemplar Pedra do Cavalo 689 de Bahía presenta mericarpos con aristas de 2 $\mathrm{mm}$ long., en el resto del material las aristas son muy breves, 0,2 mm long. Por lo demás, todo el material es muy homogéneo, destacándose del resto de las especies por el color negruzco del follaje.

\section{Sida chapadensis K.Schum.}

Schuman, K. en Mart., Fl. bras. 12 (3): 317-318. 1891. Typus: "Minas Gerës ad Chapada do Boa Vista, Riedel 1604, floret junio" (holotypus B†, foto F 9375!, isotypus NY fragmento).

Obs. Hay una Serra da Boa Vista, al sur de 
Barbacena, lugar en que Riedel estuvo en junio de 1824.

\section{Sida dictyocarpa Griseb. ex K.Schum.}

Fig. $2 \mathrm{~K}$

Schumann, K., en Mart. Fl. bras. 12 (3): 314. 1891. Lectotypus (Rodrigo, 1944): Argentina. Córdoba: Estancia Germania. Lorentz 161 (B $\dagger$ foto F 1180!, isotypi LP!, M! foto F 19685!) [non F.Muell. ex Benth., 1862, nomen ex Ind. Kew. 2: 897. 1895].

Iconografía: Rodrigo, 1944, figs. 26, 27 y lám. XIX.

Hierba perenne, hemicriptófita, decumbente. Eje central 30-40 cm alt., ramas extendidas en el suelo o apoyantes hasta $50 \mathrm{~cm}$ long. Tallo con pelos simples 2-3 mm long. y pelos glandulares pequeños, esparcidos. Estípulas lineares 4-5 mm long., con pelos largos, blancos y brillantes. Pecíolo 10-30 mm long., con tomento similar al del tallo. Lámina ovada, base acorazonada, ápice agudo, margen crenado-aserrado desde la base, 2,5-4 cm long. $x$ 1,5-2,5 cm lat.; ambas caras con pelos simples 1-1,5 mm long., adpresos. Flores axilares solitarias, largamente pediceladas, con frecuencia ramitas accesorias con flores cortamente pediceladas. Pedicelos articulados, 10-50 mm long., en las ramitas axilares 3-5 mm long., con tomento similar al del tallo. Cáliz campanulado, 6-7 mm long., lóbulos triangulares $4 \mathrm{~mm}$ long. x $2 \mathrm{~mm}$ lat. con pelos glandulares y abundantes pelos simples 1-2 mm long. Corola amarilla, pétalos 6-7 mm long. x 4-5 mm lat., glabros. Tubo estaminal 2-2,5 mm long. con pelos simples, hialinos. Ovario 5-carpelar. Mericarpos trígonos, 2,5-4,5 mm long. $x$ 1,5 mm lat. y un par de aristas apicales 1-2 mm long., cara dorsal reticulada y con el nervio medio sobresaliente, caras laterales frágiles, con retículo poco marcado, ápice con pelitos simples y aristas con pequeños pelos antrorsos. Semilla glabra, excepto pocos pelos breves en el ápice. Cromosomas $2 \mathrm{n}=16$.

Distribución geográfica: En Argentina es una especie característica del chaco árido y semi-árido, con menos de $800 \mathrm{~mm}$ de lluvia anual, donde vive en quebrachales de "quebracho colorado" [Schinopsis Lorentzii (Griseb.) Engl.] y "horco quebracho" (Schinopsis marginata Engl.); el límite sur lo constituyen las sierras de Córdoba y San Luis; también fue coleccionada en las barrancas del río Paraná, cerca de la ciudad de Paraná, en Entre Ríos. En Bolivia y Paraguay vive en ambientes similares a los de Argentina.

Etimología: Del griego dictyos $=$ red $\mathrm{y}$ carpos $=$ fruto

Material seleccionado estudiado: ARGENTINA. Catamarca: Dep. La Paz, El Moreno, 9-III1950, Brizuela 922 (CTES, LIL). Chaco: Dep. 12 de Octubre, Gral. Pinedo, 29-XII-1970, Krapovickas \& Cristóbal 17320 (CTES); Dep. Gral. Belgrano, Corzuela, 29-XII-1970, Krapovickas \& Cristóbal 17302 (CTES); Dep. Gral. Güemes, Sauzalito, 5-III-2000, Fortunato 6594 (BAB, CTES); Km 27, Picada del Canal del río Bermejo, 12-V-1970, Schulz 17398 (CTES); Dep. Mayor Luis J. Fontana, E. Urien, 5-III-1947, Schulz 6715 (LIL); Dep. 9 de Julio, Las Breñas, 26-X-1959, Schulz 10653 (CTES); Dep. O’Higgins, La Clotilde, II-1939, Schulz 2202 (CTES); Dep. Presidencia de la Plaza, Presidencia de la Plaza, 24-II-2004, Tressens \& Keller 7003 (CTES); Dep. Presidencia Saénz Peña, Bajo Hondo, VII-1935, Schulz 841 (CTES). Córdoba: El Manzano, entre San Vicente y Río Zeballos, 28-I-1881, Galander s. n. (CORD, LP); Dep. Colón, Mendiolaza, 3-V-1964, Hunziker 17420 (CORD, TES); Dep. Pocho, Sierra de Pocho, 24-III-1958, Hunziker 13472 (CORD, CTES); Dep. Ischilín, Huascha, 29-III-1996, Krapovickas \& Cristóbal 46592 (CTES, MBM, TEX); Dep. Punilla, Puerto Punilla, 700 m, 25-III-1951, Gutierrez 331 (CTES, LIL); Dep. Río Tercero, Embalse, 6-III-1966, Partridge s.n. (BAB 60068); Dep. Rio Seco, San Miguel, 29-III-1996, Krapovickas \& Cristóbal 46597 (ASU, CTES, F, MEXU, U); Dep. Sobremonte, entre Palos Secos y Ahí Veremos, 4-V-1956, Hunziker 12103 (CORD, CTES); Agua de Oro, 3-II-1955, Castellanos 3200 (LIL). Entre Ríos: Paraná, Bajada Grande, 6-XI1965, Burkart 25993 (CTES, SI). Formosa: Dep. Bermejo, Laguna Yema, 24-IV-1999, Vanni \& al. 4344 (CTES); Dep. Matacos, Ingeniero Juárez, 2- 
VI-1980, Pedersen 12896 (C, CTES); Dep. Patiño, 24 km SE de Pozo del Tigre, 21-II-1996, Krapovickas \& Cristóbal 46555 (CTES); Dep. Ramón Lista, El Quebracho, 30-XI-1983, Maranta 421 (CTES). Jujuy: Dep. El Carmen, 6-I-1971, Krapovickas \& Cristóbal 17542 (CTES); Dep. Santa Bárbara, El Fuerte, 19-I-2002, Solis Neffa \& al. 769 (CTES). La Rioja: Dep. A.V. Peñaloza, Patquia, 25-III-2000, Biurrum 6449 (CTES); Dep. Chamical, $10 \mathrm{~km}$ SW de Chamical, 19-I-1990 Biurrum 3027 (CTES); Dep. General Belgrano, Olta, 575 m, 7-VIII-1977, Biurrum 1312 (CTES); Dep. Gobernador Gordillo, 16-II-1977, Biurrum 646 (CTES). Salta: Dep. Anta, 10 km N de J.V. González, 4-III-1958, Morello \& Cuezzo 388 (LIL); Puesto Los Toritos (finca San Javier), 13III-1958, Morello \& Cuezzo 60 (LIL); Puerta del Mistol, 15-V-1959, Cuezzo 1098 (LIL); Choya, El Salvador, 20-V-1961, de la Sota \& Legname 950 (LIL); between Macapillo \& N.S. de Talavera, 11XI-1974, Pedersen 10829 (C, CTES); Dep. Metán, Metán Viejo, 28-III-1975, Krapovickas \& Cristóbal 27936 (CTES); Metán, S. José de Orquera, 18-XII-1957, Villa Carenzo 16 (LIL); Dep. Rivadavia, Alto de la Sierra, 5-II-1984, Maranta 691 (CTES); Dep. San Martín, Gral. Ballivián, 4-IV-1977, Krapovickas \& Schinini 30932 (CORD, CTES, MCNS). San Juan: Dep. Valle Fértil, S. Agustín del Valle Fértil, 23-XI1986, Haene 565 (CTES, SI). San Luis: Estanzuela, 4-III-1882, Galander s.n. (CORD, LP); Dep. Ayacucho, Luján, 3-IX-1982, Rosa 275 (CTES). Santiago del Estero: Copo, Obraje Los Tigres, 20-IX-1971, Meyer \& Vaca 23354 (LIL); Los Tigres, 23-IV-1970, Roic 600 (LIL). Tucumán: Burruyacu, río Medina, Los Pinos, 1600 m, 26-I-1963, Krapovickas \& Legname 10769 (LIL). BOLIVIA. Chuquisaca: Carandaytí, 13-IV-1977, Krapovickas \& Schinini 31283 (CTES, LPB). Santa Cruz: Pailón, 21-I-2004, Solís Neffa \& al. 1070 (CTES). Tarija: Palmar Grande, 10-IV-1977, Krapovickas \& Schinini 31081 (CTES) PARAGUAY. Alto Paraguay: Mayor Pedro Lagerenza, 7-IV-1978, Schinini \& Bordas 15220 (CTES). Boquerón: Tte. Ochoa, 11-XII1987, Schinini \& Palacios 25564 (CTES, FCQ, G, MO). Presidente Hayes: Ea. La Per-

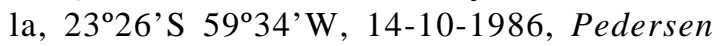
14628 (C, CTES).

\section{Sida Emilei Hochr.}

Fig. $2 \mathrm{~L}$

Hochreutiner, B.P.G., Annuaire Conserv. Jard. Bot. Genève 20: 138. 1917. Typus: Paraguay, Concepción, zwischen río Apa und río Aquidabán, Centurión, 26-X-1908-1909, Fiebrig 4137 (holotypus $\mathrm{G}$ !, isotypus $\mathrm{K}$ !).

Sida chacoensis Hassl., Add. Pl. Hassl.: 15. 1917. nomen nudum. "Fiebrig 1470, 1418a".

Subarbusto erecto, 0,40-1,50 m alt. Tallo hirsuto, cubierto de pelos estrellados con radios 0,5-1 mm long. y con cierta frecuencia también pelos simples $2 \mathrm{~mm}$ long., esparcidos. Estípulas lineares, 2-7 mm long., hirsutas. Pecíolo 1-5 cm long., hirsuto, pelos estrellados. Lámina hasta $7 \mathrm{~cm}$ long. x 3,5 cm lat., ovada, de base cordada y ápice agudo, margen crenado-aserrado desde la base, ambas caras hirsutas con pelos estrellados. Flores axilares con pedicelos 3-13 mm long., articulados, hirsutos; con frecuencia en la axila glomérulos o ramitas paucifloras con pedicelos breves, 1-2 mm long. Cáliz campanulado 6-9 mm long., lóbulos triangulares hasta 6 $\mathrm{mm}$ long. x $5 \mathrm{~mm}$ lat.; margen y nervios principales verde más oscuro; cara externa cubierta de pelos estrellados pequeños, algo mayores, 0,5 mm long. sobre los nervios y márgenes; cara interna con pelos simples antrorsos hacia el ápice de los lóbulos y en el nervio medio. Corola amarilla, pétalos hasta $12 \mathrm{~mm}$ long., uña glabra. Tubo estaminal $3 \mathrm{~mm}$ long., con pelos simples y estrellados hialinos. Ovario 5-carpelar. Mericarpos trígonos, 2,5-3 mm long. $\mathrm{x} 1 \mathrm{~mm}$ lat., reticulados, aristas apicales 1,5-2 mm long. con pelos simples antrorsos. Semilla glabra, excepto el ápice.

Distribución geográfica: Especie principalmente del chaco paraguayo, crece también en el oeste de Paraguay Central, en el sur de Mato Grosso, en Brasil y en el departamento de Santa Cruz, en Bolivia.

Etimología: Nombre dedicado al Dr. Émile Hassler (1864-1937). 
Material adicional estudiado: BOLIVIA. Santa Cruz: prov. Cordillera, Cabezas, $420 \mathrm{~m}$, 4-III1945, Peredo 349 (LIL); prov. Chiquitos, El Carmen, 31-III-1959, Krapovickas 10011 (CTES); San José, 300 m, 26-IV-1980, Krapovickas y Schinini 36541 (CTES); 2 km E de Roboré, 300 m, 21-IV-1980, Krapovickas \& Schinini 36363 (CTES); 4 km S de Roboré, 23-IV-1980, Krapovickas \& Schinini 36494 (CTES); prov. Sandoval, San Matías, 18-IV-1980, Krapovickas \& Schinini 36221 (CTES). BRASIL. Mato Grosso do Sul: 26 km E de Porto Murtinho, 29-VI-1977, Krapovickas \& Schinini 32787 (CTES). PARAGUAY. Alto Paraguay: Fuerte Olimpo, 24-X-1946, Rojas 13654 (CTES, LIL); Fuerte Olimpo, 20-XI-1946, Rojas 13654a (CTES, LIL); Mayor Pedro Lagerenza, río Timane, 8-IV-1978, Schinini \& Bordas 14859 (CTES); Cerro León, 30-IX-1979, Schinini \& Bordas 17851(CTES); Piquete Histórico, km 30, $25 \mathrm{~km}$ SE de Lagerenza, $250 \mathrm{~m}$, Spichiger \& al. 2590 (CTES, G); Cerro León, 500 m, 17-V-1988, Charpin \& Ramella 21666 (CTES, G); Cerro León, 350 m, 16-IV-1989, Ramella 2200 (CTES, G); 2 km N del cruce LagerenzaAgua Dulce, Parque Defensores del Chaco, 17-IV1997, Mereles 6619 (CTES, FCQ). Concepción: entre Paso Horqueta y Concepción, 25-II-1968, Krapovickas \& al. 14228 (BAA, CTES, FCQ, G, MO, SI). Paraguarí: Cerro Pelado, près de Parguarí, 3-IV-1883, Balansa 4381 (P); Paraguarí, 29-XI-1950, Sparre \& Vervoorst 701 (CTES, LIL). Central: Asunción, 15-V-1874, Balansa 1630 (P); Tarumandy, 1-V-1972, Schinini $4698 b$ (CTES).

\section{Sida esperanzae R.E.Fr.}

Fig. $2 \mathrm{M}$

Fries, R.E., Ark. Bot. 6(2): 8-9, Taf. 2, figs. 1113. 1906. Lectotypus (Rodrigo, 1944): Argentina. Jujuy: Dep. San Pedro, Esperanza, 12-IX-1901, Fries 540 (S!, isotypus CORD!).

Sida glutinosa Cav. var. longearistata Monteiro, Lilloa 17: 525, 1949. Typus: Argentina. Salta; Dep. Orán, Urundel, río Colorado, 20-I-1945, Krapovickas 1556 (holotypus RBR!, isotypi LIL!, $\mathrm{S} !)$.

Iconografía: Rodrigo 1944, lám. XX.
Hierba 0,5-1 m alt. Tallo, pecíolo y pedúnculo cubierto de una capa densa de pelos glandulares y a veces algunos pelos simples de $2 \mathrm{~mm}$ long. esparcidos. Estípulas lineares, 2-5 mm long., retrorsas, pilosas. Pecíolo más breve que la lámina, 5-30 mm long., cubierto de pelos glandulares. Lámina ovada, base cordada, ápice agudo, margen crenado-aserrado, hasta $8 \mathrm{~cm}$ long. x $6 \mathrm{~cm}$ lat.; haz con pelos estrellados muy pequeños y algunos pelos simples hacia el ápice, envés con pelos estrellados. Flores solitarias axilares, pedicelos 10-27 mm long.; en la axila suele haber una ramita de hasta $1 \mathrm{~cm}$ long. con 2-3 flores con pedicelos 1-3 mm long. Pedicelos articulados en la mitad superior. Cáliz con pelos glandulares en toda la superficie, tubo 3-3,5 mm long., lóbulos triangulares, agudos, 3-4 mm long. x 2,5-3 mm lat. Corola amarilla, pétalos $4 \mathrm{~mm}$ long., glabros. Tubo estaminal 2,5 mm long. con pelos simples hialinos. Mericarpos 5 , trígonos, con las caras reticuladas, consistentes, $3 \mathrm{~mm}$ long., con algunos pelos muy breves en el dorso, y 2 aristas apicales 1,5-2 $\mathrm{mm}$ long., con pelos antrorsos. Semilla trígona, glabra, salvo algunos pelos en el ápice.

Distribución geográfica: Especie del noroeste de Argentina, del este de Bolivia y del chaco paraguayo.

Etimología: El nombre S. esperanzae está dedicado al Ingenio Azucarero Esperanza, situado en las cercanías de la ciudad de San Pedro, en la provincia argentina de Jujuy.

Material estudiado: ARGENTINA. Catamarca: Dep. Ambato, Los Varela, 1390 m. 28-III1995, Saravia Toledo \& al. 12954 (CTES); Dep. Capayán, Sierra de Ambato, Quebrada de San Jerónimo, 700-800 m, 21-II-1984, Hunziker \& Di Fulvio 17006 (CORD, CTES). Córdoba: Dep. Pocho, Sierra de Pocho, 500 m, 16-I-1960, Hunziker 14696 (CORD, CTES); Dep. Sobremonte, entre San Francisco del Chañar y Las Chichas, 4-V1956, Hunziker 12201 (CORD, CTES); Dep. Totoral, Simbolar, 6-II-1951, A. de la Sota 3747 (CTES, LIL). Formosa: Dep. Matacos, Ing. Juárez, 16-X-1962, Bordón 64 (CTES); Dep. Ramón Lista, La Rinconada, 31-V-1982, Molina \& Cabral 329 (CTES). Jujuy: Dep. El Carmen, entre 
Agua Caliente y San Antonio, 700 m, 12-V-1990, Novara 9842 (CTES, MCNS); Dep. San Pedro, San Pedro, 10-V-1948, Krapovickas 4779 (CORD, CTES, LIL); San Pedro, 9-V-1971, Krapovickas \& al. 18632 (CTES, LP); 5 km E de San Pedro, río Grande, 10-V-1983, Krapovickas \& Schinini 39303 (CTES, HAS, MICH, UC); Arroyo del Medio, 15-II-1988, Magnoni \& al. 31 (CTES, MCNS); Dep. Santa Bárbara, Sauce Guacho, 15-IV-1983, Ahumada 4788 (CTES, JUA); Finca La Campana, 12-XII-1998, Ahumada 8880 (CTES, JUA). La Rioja: Dep. Chamical, Chamical, 27-III-1990, Biurrum 3276 (CTES); Las Amoladeras, 23-I1998, Biurrum 5068 (CTES); $10 \mathrm{~km} \mathrm{SE} \mathrm{de}$ Chamical, 19-I-1990, Biurrum 3033 (CTES); Dep. Gral. Belgrano, entre Chamical y Chañar, Las Vizcacheras, 11-V-1990, Biurrum 3394 (CTES); Dep. Gobernador Gordillo, Polco, 7-II-1978, Biurrum 1318 (CTES); Sierra de Los Llanos, Quebrada de Polcos, 700-800 m, 20-II-1964, Hunziker \& Di Fulvio 16932 (CORD, CTES). Salta: Dep. Anta, El Quebrachal, 10-II-1951, Luna 158 (BA, CTES, LIL); Los Colorados, 250 m, 4-III-1992, Saravia Toledo 10697 (CTES); Finca Laguna Blanca, 15-V-1959, Morello \& Cuezzo 1125 (CTES, LIL); Dep. Cafayate, Cafayate, 1700 m, 8I-1972, Krapovickas \& Cristóbal 20718 (CTES); Dep. Campo Santo, 23 km E de Güemes, 2-VI1970, Legname \& Cuezzo 7549 (CTES, LIL); Dep. La Viña, Cabra Coral, 6-I-1974, Krapovickas \& Cristóbal 24528 (CTES); Dep. Metán, ruta 34, y río Juramento, 9-V-1971, Krapovickas \& al. 18602 (CTES); Metán Viejo, 28-III-1975, Krapovickas \& Cristóbal 27937 (CTES, MCNS); Metán, 28-III-1975, Krapovickas \& Cristóbal 27940 (CORD, CTES, MBNS, MO, NY); El Tunal, 9XI-1974, Krapovickas \& Cristóbal 26719 (CTES); Dep. Orán, Elordi, 2-VI-1963, Legname \& Cuezzo 4056 (CTES, LIL); 12 km S de La Estrella, 8-IV-1996, Krapovickas \& Cristóbal 46709 (CTES); 10 km E de La Estrella, 500 m, 3-V-1999, Krapovickas \& Seijo 47677 (CORD, CTES, MCNS); Dep. Rivadavia, Los Blancos, 9-IV-1996, Krapovickas \& Cristóbal 46739 (CTES); Los Blancos, 2-V-1999, Krapovickas \& Seijo 47663 (CTES); Dep. Rosario de la Frontera, 20 km E de Rosario de la Frontera, 29-III-1975, Krapovickas \& al. 28011 (CTES); entre Horcones y El Bordo, 21-XI-1994, Krapovickas \& Cristóbal 46249 (CTES, MCNS, MO); Dep. San Martín, Hickmann, 8-V-1999, Krapovickas \& Seijo
47741 (CTES, MCNS). San Juan: Dep. Valle Fértil, entre Usno y Baldes del Rosario, 10-IV1006, Biurrum 4387 (CTES); San Agustín del Valle Fértil, 18-XI-1986, Haene 434 (CTES, SI); de Marayes a Las Tumanas, 11-XI-1980, Kiesling 3026 (CTES, SI). San Luis: Dep. Belgrano, Suyuque Nuevo, 22-II-1990, Del Vitto \& al. 5101 (CTES). Santiago del Estero: Dep. Copo, Mistolito, 1-IV-1949, Luna 1438 (CTES, LIL). Tucumán: Dep. Tafí, Reserva Forestal, cerca del Cadillal, 1-I-1969, Krapovickas \& Cristóbal 14515 (CTES); Dep. Trancas, Vipos, 10-II-1983, Renolfi 281 (CTES); 6 km S de Vipos, 6-I-1969, Krapovickas \& Cristóbal 14543 (CTES). BOLIVIA. La Paz: Prov. Sud Yungas, Pasto Grande, valle del río Chungamayu, 1340 m, 1-V-1995, Beck 22449 (CTES, LPB). Santa Cruz: Prov. Cordillera, Lagunillas, 950 m, 15-IV-1977, Krapovickas \& Schinini 31351 (CTES, LPB). Tarija: Prov. Arce, abra de la Cruz, camino a Padcaya, 1820 m, 31I-1988, Liberman \& al. 1932 (CTES, LPB); Prov. Avilés, Chocloca, 25-III-1979, Beck 741 (CTES, LPB); Prov. Gran Chaco, Ysyri, 40 km W de Villa Montes, 500 m, 26-V-1971, Krapovickas \& al. 19283 (CTES, LPB, MO, TEX); Villa Montes, 28-V-1971, Krapovickas \& al. 19348 (CTES, SI); Palmar Grande, 10-IV-1977, Krapovickas \& Schinini 31080 (CTES, LPB); Prov. O’Connor, Entre Ríos, 1330 m, 21-V1971, Krapovickas \& al. 19064 (CTES); Puerto Margarita, río Pilcomayo, 2-V-1983, Krapovickas \& Schinini 39105 (CTES, LPB, UC). PARAGUAY. Boquerón: ruta Transchaco,

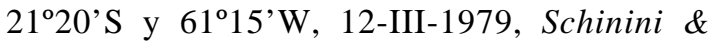
Bordas 16604 (CTES, FCQ, G, MO); Filadelfia, 1-III-1991, Vanni \& al. 2536 (CTES); Nueva Asunción, 14-V-1994, Krapovickas \& al. 45400 (CTES, FCQ). Presidente Hayes: Isla Poí, 11XII-1992, Krapovickas \& Cristóbal 44336 (CTES, FCQ, G, MO); Isla Poí, 16-V-1994, Krapovickas \& al. 45495 (CTES, FCQ, G, MBM, MO).

\section{Sida glutinosa Comm. ex Cav.}

Fig. 2 I

Cavanilles, A. J., Diss. 1: 16, t. 2, f. 8. 1785. Lectotypus, aquí designado: Francia [Mauritius], 
Commerson s.n. (MPU!, isotypus P-JU 12278A!) [non Roxb., 1832] Ver Obs. 2.

Sida nervosa DC., Prodr. 1: 465. 1824. Typus: Santo Domingo, Bertero s.n. (holotypus G-DC, isotypus W foto $\mathrm{F} 33387$ !).

Sida fasciculata Willd. ex Spreng., Syst. Veg. 3: 113. 1826. Typus: Venezuela, Cumaná, Humboldt \& Bonpland s.n. (holotypus B-W 12691 foto!, isotypus P!) [non Torrey \& A.Gray, 1838].

Sida Endlicheriana C. Presl, Reliq. Haenk. 2: 111. 1835.

Sida Willdenowii D. Dietr., Syn. Pl. 4: 1847. Nom. superf. para $S$. fasciculata.

Sida piauhyensis Ulbrich., Bot. Jahrb. Syst. 42: 226-227. 1909. Typus: Brasil, Serra da Lagoa, Januar 1907, Ule 7461 (holotypus B† foto F 9389, Rodrigo, 1944, lám. XVIII). Syn. nov., aquí propuesto.

Sida insperata Standl. \& L.O. Williams, Ceiba 3: 51. 1952. Typus: Honduras, Morazón, El Zamorano, Standley 24639 (holotypus US!, isotypus P!).

Iconografía: Fuertes Aguilar, 1995: 44, fig. 6.

Hierba erecta 0,50-2 m alt. Tallo cubierto de pelos glandulares breves y pelos simples o estrellados 1-2 mm long. Estípulas lineares, retrorsas, caducas, 1-4 mm long., glabras, margen piloso. Pecíolo 1-7 cm long. Láminas de ovadas a oblongas, las superiores lanceoladas, $1-14 \mathrm{~cm}$ long. $x \quad 0,5-8 \mathrm{~cm}$ lat., base cordada, margen crenado-aserrado, ambas caras con pelos estrellados. Flores axilares, solitarias y por decrecer el tamaño de las hojas, en panículas terminales. Pedicelo 10-25 mm long., articulado en la mitad superior, con pelos glandulares y pelos simples breves, algo antrorsos. Cáliz 4-5 mm long., dientes triangulares, $2 \mathrm{~mm}$ long. x 2,5 mm lat., iguales o más breves que el tubo, nervios y márgenes de los sépalos más oscuros, con pelos glandulares, simples y estrellados sobre los nervios y márgenes de los sépalos. Corola amarilla, pétalos 4-5 mm long., uña pilosa. Tubo estaminal 1-2 mm long. con pelos estrellados abundantes. Ovario con 5 carpelos. Mericarpos trígonos, 2-3 mm long., dehiscentes en el ápice y con dos aristas apicales 0,5-2 mm long., aristas y dorso con pelos antrorsos, caras laterales y dorso levemente reticulados, frágiles. Semilla trígono-obovada, glabra.
Cromosomas $2 \mathrm{n}=16$.

Distribución geográfica: En América su área se extiende desde México hasta el noreste de Brasil, donde fue coleccionada en Ceará, Goiás, Maranhão y Minas Gerais.

Material adicional estudiado: BRASIL. Ceará: Floresta, Serra da Meruoca, 19-VII-1955, Fernandes 1435 (CTES, EAC). DF: Fercal, Brasilia, 20V-1967, Heringer 11505 (CTES, UB). Goiás: 1,5 km S de JK (Mun. Formosa), 15-IV- 1983, Krapovickas \& al. 38828 (CEN, CTES). Maranhão: Ilha de Balsas (Mun. Loreto), 300 m, 30-IV-1962, Eiten \& Eiten 4459B (CTES). Minas Gerais: Paraopeba, 5-V-1058, Heringer 6411 (UB, CTES); rio das Velhas, camino a Diamantina, 29IV-1961, Gregory \& al. 10505 (CTES, LIL, SI).

Obs. 1. Cavanilles (1785: 16) en la descripción original de Sida glutinosa cita con dudas a $S$. racemosa Burm.(1768) como posible sinónimo. Merrill (1921: 364) basado en la descripción original de $S$. racemosa, afirma que se trata de $S$. mysorensis Wight. \& Arn. Borssum Waalkes (1966: 181, 191) no pudo encontrar el tipo de $S$. racemosa, y basado en razones geográficas, supone que es más probable que sea sinónimo de $S$. mysorensis que de S. glutinosa.

Obs. 2. En el protólogo Cavanilles dice: "Habitat in insulis S. Dom. \& Franciae. Hic eam observavit Commerson. V.S. á D. Thouin, \& aliud exemplar americanum á D. de Jussieu”. El herbario de Thouin pasó a manos de Cambessêdes quién lo depositó en Montpellier (MPU) (Stafleu \& Cowan, 1986, 6: 297). En el herbario de Montpellier se encuentra el ejemplar Ile de France, C[ommers]on. que debe considerarse como el lectotipo.

Borssum Waalkes (1966: 190) designa como lectotipo el ejemplar P-JU 12278A, leg. Commerson, Ile de France.

En el herbario de Jussieu (P-JU) bajo el número 12278 hay dos ejemplares. El A de Ile de France leg. Commerson y el B de St. Domingue, leg. Mazure.

Garilleti (1993: 127-128) recoge la información de Borssum Waalkes (1966) y señala la presencia en MA de dos ramas en fruto que 
corresponden a los dos ejemplares de P-JU.

Obs. 3. Gandoger (1924) divide a S. glutinosa en tres microespecies (?) con nomenclatura binaria, dos de Cuba y una de "Brasilia, Rio de J. (Dusén)” que denomina S. longepilosa Gand., sin diagnosis. La frase de la clave en latín: "patulo et longepilosa" no es suficiente para reconocerla.

\section{Sida goyazensis K.Schum.}

Fig. $2 \mathrm{C}$

Schumann, K., en Mart., Fl. bras. 12(3); 316217, 1891. "Brasil, Goyaz inter S. Cruz et Brajon: Pohl n. 2850 (d.n. 1312)” (B† foto F 9380!, lectotypus, aquí designado: $\mathrm{W}$ !).

Subarbusto erecto, $40-50 \mathrm{~cm}$ alt. Tallo cubierto de pelos glandulares pequeños y con frecuencia pelos simples, $2 \mathrm{~mm}$ long., esparcidos. Estípulas 2-4 mm long. lineares, hirsutas. Pecíolo 2-6 cm long. Lámina 2-19 cm long. x 1-6 cm lat., ovada u ovado-oblonga, base cordada, ápice agudo, margen crenadoaserrado, haz con pelos simples $0,5-1 \mathrm{~mm}$ long., adpresos, esparcidos, envés con pelos estrellados. Flores axilares solitarias, en la axila suele haber una ramita florífera con hojas pequeñas. Pedicelos 10-50 mm long., articulados en el tercio superior, con pelos glandulares abundantes y pelos simples $1 \mathrm{~mm}$ long., esparcidos. Cáliz 7-8 mm long., lóbulos triangulares, $3 \mathrm{~mm}$ long. $\mathrm{x} 3 \mathrm{~mm}$ lat., nervios principales y margen de los lóbulos verde más oscuro; cara externa con pelos glandulares en toda su superficie y pelos simples, mayores en los nervios principales y en el margen de los lóbulos, cara interna con una hilera de pelos simples adpresos en la línea media. Corola amarilla, pétalos $9 \mathrm{~mm}$ long. x $7 \mathrm{~mm}$ lat., uña pilosa. Tubo estaminal $3 \mathrm{~mm}$ long., glabro. Ovario 5-carpelar. Mericarpos trígonos, 2,5-3 mm long. x 1,5-2 mm lat., múticos, cara dorsal lisa, caras laterales papiráceas, hacia el ápice pocos pelos simples muy pequeños. Semilla glabra.

Distribución geográfica: Vive en el centro de Brasil, en los estados de Goiás y Tocantins. Crece en ambientes modificados (“capoeiras”).

Material estudiado: BRASIL. Goiás: Goiânia, 24-V-1968, Rizzo \& Barbosa 1056 (CTES, UFG); 30 km NE de Formosa (estrada Brasilia-Barreiras), 25-IV-1961, Gregory \& al. 10445 (LIL). Tocantins: Rodovia Campos Belos-Taguatinga, $12 \mathrm{~km} \mathrm{~N}$ de Aurora do Tocantins, $500 \mathrm{~m}, 10-\mathrm{V}-2000$, Hatschbach \& al. 70841 (CTES, MBM); TO-110, 6 km N de Novo Alegre, 500 m, 10-V-2000, Hatschbach \& al. 70809 (CTES, MBM).

\section{Sida gracilipes Rusby}

Fig. $2 \mathrm{O}$

Rusby, H.H., Mem. Torrey Bot. Club 6: 10. 1896. "Cochabamba, 1891 ([Bang] 1146)" (holotypus NY!, isotypi G!, US!).

Subarbusto de $30-70 \mathrm{~cm}$ alt. Tallo cubierto de una capa de pelos estrellados muy pequeños, con algunos pelos glandulares y algunos pelos simples 1-2 mm long., esparcidos. Estípulas lineares, 3-7 mm long., pilosas, algo retrorsas. Pecíolo 1-3 cm long., con tomento similar al del tallo. Lámina 2-7 cm long. x 1$3,5 \mathrm{~cm}$ lat., ovada, base cordada y ápice agudo, margen crenado-aserrado, haz con pelos simples $1 \mathrm{~mm}$ long., adpresos, esparcidos, a veces también en las hojas jóvenes pelos estrellados pequeños, envés con pelos estrellados que dejan ver la epidermis. Flores axilares, solitarias y por decrecer el tamaño de las hojas, en panículas terminales. Pedicelos 20$40 \mathrm{~mm}$ long., generalmente exceden las hojas, articulados en el tercio superior, con tomento similar al de los tallos. Cáliz campanulado, 8$11 \mathrm{~mm}$ long., lóbulos triangulares, acuminados, 4-5 mm long., con pelos glandulares y pelos estrellados pequeños, margen de los lóbulos y nervios verde más oscuro, hirsutos. Corola amarilla, pétalos 12-13 mm long., uña glabra. Tubo estaminal con pelos simples hialinos. Ovario con 5 carpelos. Mericarpos trígonos, 3-4 mm long. $x$ 1,2-1,5 mm lat., submúticos o con aristas hasta $1 \mathrm{~mm}$ long., glabros o con algunos pelos muy breves hacia el ápice, caras laterales y dorso reticulados, 
tenaces. Semilla glabra, sólo con pelos en el ápice.

Distribución geográfica: Vive en Bolivia en los departamentos de Chuquisaca, Cochabamba y Santa Cruz, en valles subáridos entre 1500 y 2500 m, especialmente en bosques de Schinopsis Haenkeana Endl.

Nombres vernáculos: "Bervenita" (Teran BN149); "Ismowagachi” (Caballero HR-38).

Material adicional estudiado: BOLIVIA. Chuquisaca: Prov. Tomina, Corso, $8 \mathrm{~km}$ de Tomina, 2100 m, 27-II-1994, Teran BN149 (CTES). Cochabamba: Prov. Campero, Com. Suero Mayu, 2330 m, 25-I-1990, Caballero HR-38 (CTES); camino de Aiquile a Villa Granado, 2170 m, 1-V-1999, Antezana 1220 (CTES); Puente Mizque, 2240 m, 21-I-1993, Antezana 579 (CTES); de Peña Colorada a Villa Granado, 1500 m, 21-III1999, Antezana 1149 (CTES); Peña Colorada, 1830 m, 13-IV-1999, Antezana 1209 (CTES); Cabra Muerta, 2190 m, 1-V-1999, Antezana 1223 (CTES); Prov. Quillacollo, Parotani, 2450 m, III1951, Cárdenas 4790 (LIL); Quillacollo, 22 km hacia Oruro, 2480 m, 31-III-1979, Beck 907 (CTES, LPB). Santa Cruz: Prov. Caballero, Estancia Lanza-Lanza, $2 \mathrm{~km}$ del río Comarapa, 1600 m, 22-I-1995, Gutiérrez \& al. 1542 (CTES, USZ).

Tarija: prov. Méndez, Rio Pilaya Camaron, 1920 m, 4-II-1982, Gerold 146 (CTES, LPB).

\section{Sida gracillima Hassl.}

Fig. $2 \mathrm{~J}$

Hassler, E., Feddes Repert. 8: 35-36. 1910. Typus: Paraguay. Concepción: San Luis, Fiebrig 5173 (holotypus G foto F 23741!, isotypi BM!, M!).

Hierba perenne, 1,50-2 m alt., apoyante. Tallo glabro, en el extremo apical algunos pelos estrellados muy pequeños. Estípulas lineares, agudas, persistentes, 5-7 mm long., con un nervio medio sobresaliente, glabrescentes. Pecíolo 10-15 mm long., glabro, salvo algunos pelos estrellados diminutos hacia el ápice. Lámina triangular-lanceolada oval- oblonga, 25-60 mm long. x 7-25 mm lat., base cordada, ápice agudo, margen crenado-aserrado, en hojas muy jóvenes haz con pelos simples muy pequeños, esparcidos, envés con pocos pelos estrellados mayores, hojas adultas glabras. Flores axilares, solitarias, Pedicelos 20-60 mm long., glabros, articulados $5 \mathrm{~mm}$ por debajo del cáliz. Cáliz turbinado, glabro, $8 \mathrm{~mm}$ long., dientes triangulares $5 \mathrm{~mm}$ long. $\mathrm{x}$ 2,5 mm lat., margen algo más oscuros y con pelos simples muy pequeños. Corola amarilla, pétalos 9-10 mm long., glabros. Tubo estaminal 2,5-3 mm long. con pelos simples, hialinos, esparcidos. Mericarpos 5, trígonos, $3 \mathrm{~mm}$ long. x $1 \mathrm{~mm}$ lat., aristas $1 \mathrm{~mm}$ long., caras reticuladas, ápice con pelos simples pequeños y aristas con pelos antrorsos muy pequeños. Semilla trígono-redondeada, $2 \mathrm{~mm}$ long. $\mathrm{x} 1$ mm lat., base aguda, ápice aplanado con pelos blancos, el resto glabro.

Distribución geográfica: Conocida solamente por la colección tipo.

\section{Sida Jussieana DC.}

De Candolle, A.P., Prodr. 1: 463. 1824. Typus: Perú, [Jussieu] (holotypus P-JU 12267!) p.p.

Sida decumbens A.St.-Hil. \& Naudin, Ann. Sci. Nat. ser.2, 18: 53. 1842. Typus: Brasil, Minas Gerais, Congonhas, Vauthier 21 (holotypus P! foto F 35535!).

Sida stolonifera Salzm. ex Turcz., Bull. Soc. Imp. Naturalistes Moscou 31: 199. 1958. Typus: Brasil, Bahía, Salzmann s.n. (holotypus KW, isotypi $\mathrm{K}, \mathrm{MO}, \mathrm{P}$ ).

Anoda decumbens (A.St.-Hil. \& Naudin) Hochr., Annuaire Conserv. Jard. Bot. Genève 20: 56. 1916.

Physalastrum stoloniferum (Salzm. ex Turcz.) Monteiro, Anais XX Congr. Nac. Soc. Bot. Brasil: 402. 1969.

Iconografía: Fuertes Aguilar, 1995, fig. 2. Rodrigo, 1944, figs. 7, 12 y lám. XI.

Hierba anual o bienal, rastrera, con raíces adventicias, ramas hasta $2 \mathrm{~m}$ long. Tallo sólo con pelos simples 1-2 mm long., o también acompañados por pelos estrellados más breves y pelos glandulares muy pequeños. Estí- 
pulas lineares, 1-2 mm long. margen ciliado. Pecíolo 1-4 cm long. con tomento similar al del tallo y con una línea densa de pelos simples, blanquecinos en la cara superior. Lámina ovada, asimétrica, base cordada, ápice agudo y margen crenado-aserrado desde la base, ambas caras con pelos simples 1-2 mm long., adpresos, esparcidos, en el envés pueden presentarse pelos estrellados sobre los nervios. Flores axilares solitarias, pedicelo 10-40 mm long., con pelos simples 2 mm long., articulado en el tercio superior. Cáliz en la antesis 4-5 mm long., lóbulos triangulares $2,5 \mathrm{~mm}$ long. x $2 \mathrm{~mm}$ lat., en el fruto 8-10 $\mathrm{mm}$ long. con lóbulos $8 \mathrm{~mm}$ long. x $6 \mathrm{~mm}$ lat., de base acorazonada, cara externa con algunos pelos estrellados de 3 radios, adpresos y abundantes pelos simples $2 \mathrm{~mm}$ long. en la base. Corola amarillo pálido, raro blanca, pétalos $7 \mathrm{~mm}$ long. $\mathrm{x} 5 \mathrm{~mm}$ lat., margen con pelos muy breves, uña con pelos simples, blancos, mayores. Tubo estaminal 1-2 mm long., con pelos hialinos. Ovario 5-carpelar. Mericarpos múticos, 2 $\mathrm{mm}$ long. $\mathrm{x} 1,5 \mathrm{~mm}$ lat., dorso convexo, finamente reticulado, caras laterales lisas, frágiles. Cromosomas $2 n=16$.

Distribución geográfica: En Argentina y Bolivia vive en la selva al pie de los Andes. En Brasil sólo en el Nordeste. También ha sido coleccionada en México, Centramérica, Colombia y Venezuela.

Etimología: Nombre dedicado a Joseph de Jussieu (1704-1779), quién coleccionó el ejemplar tipo en Perú.

Material adicional estudiado: ARGENTINA. Jujuy: Vinalito, Yuto, VII-1937, Cabrera 4063 (LP). Salta: Dep. Orán, Orán, 362 m, 20-VI1944, Schulz 5006 (CTES, LIL); Santa María, 26-VI-1944, Willink 26 (CTES, LIL); Dep. San Martín, Gral. Ballivian, 4-IV-1977, Krapovickas \& Schinini 30933 (C, CTES, F, G, MBM, MO, SI); Pocitos, 31-V-1971, Krapovickas \& al. 19421 (BA, BAB, CTES, MBM, P, UC); Yariguarenda, 7-V-1998, Krapovickas \& al. 47267 (CTES, F, ILLS, MEXU, SPF). BOLIVIA. Santa Cruz: Alto Parapetí, 800 m, 30-IX-1985, Michel \& al. 406 (CTES, LPB). Tarija: Caiza, 7-
IV-1977, Krapovickas \& Schinini 30988 (C, CTES, F, MO, SI); Entre Ríos, 29-IV-1983, Krapovickas \& Schinini 38850 (CTES, LPB); Ipa, 3-VI-1971, Krapovickas \& al. 19457 (CTES). BRASIL. Bahia: Alvorada, 2-VII.1964, Pires 58147 (CTES, NY, UB). Ceará: Cedro, Luetzelburg 23592 \& 23738 (M); Aiuaba, 400 m, 25-IV-1996, Figueiredo 585 (CTES, EAC); 40 km E de Sobral, 12-IV-1967, Krapovickas 12940 (CTES). Goiás: Rio Maranhão, 12-IV-1961, Gregory \& al. 10238 (CTES, G, LIL, MO, SI). Maranhão: 25-30 km S of Loreto, 200-300 m, 6IV-1962, Eiten \& Eiten 4101 (CTES, SP). Minas Gerais: 23-VIII-1964, Irwin \& Soderstrom 5521 (CTES, NY). Piaui: 27 km E de Oeiras, 330 m, 8IV-1983, Krapovickas \& al. 38770 (CEN, CTES). MÉXICO. Chiapas: Comalapa, 770 m, 5-XI1980, Fryxell \& Lott 3312 (CTES); Guerrero, Dos Caminos, 690 m, 24-XI- 1983, Koch \& Fryxell 83260 (CTES). Veracruz: Tlalixcoyan, 10-XII1972, Krapovickas \& Cristóbal 23501 (CTES). VENEZUELA. Portuguesa: Guanare, 8-III1985, Aymard 3438 (CTES, PORT). Sucre: San Pedrito, 11-II-1983, Galantón 62 (CTES).

Obs. La posición de esta especie en la sección Nelavaga es discutible. Hochreutiner (1916) la ubica en el género Anoda Cav. por presentar mericarpos con paredes laterales frágiles. Rodrigo (1944) la ubica en la sección Physalodes Griseb. (= Krapovickasia Fryxell) por su cáliz acrescente y por sus mericarpos múticos. En cambio Fryxell (1985, 1988) la ubica en la sección Nelavaga, opinión compartida por Fuertes Aguilar (1995). Sida Jussieana es una especie fácilmente reconocible que se diferencia del resto de la sección Nelavaga por sus hojas asimétricas, por su cáliz acrescente y por la posición de sus hojas, dísticas en ramas adultas y espiraladas en ramas jóvenes. Posiblemente su ubicación tendría que ser reevaluada.

\section{Sida laciniata Bovini}

Bovini, M.G., Eugeniana 25: 23-25, fig. 1. 2001. Typus: Brasil, Minas Gerais, Januária, vale do rio Peruaçu, a caminho do cerrado do Judas, 21-VII-1997, A. Salino 3297 \& J.R. Stehmann 
(holotypus BHCB, n.v.).

Distribución geográfica: Conocida sólo por la colección tipo.

\section{Sida Luschnathiana Steud.}

Fig. 2 B

Steudel, E.G., Nomencl. Bot. Ed. 2, 2: 578, 1841. Nom. nov. para Sida viscidula Klotzsch 1840 [non Blume, 1825].

Sida viscidula Klotzsh, Linnaea 14: 301. 1840. "in campis ad Cruz de Casma pr. Bahiam, jul." (holotypus $\mathrm{B} \dagger$ foto F 9385!). Lectotypus, aquí designado: Brasil, Bahia, Campos, Crus de Casma [Cruz das Almas], july 35, [Luschnath] n. 10, Martii Herbar Florae Brasil n. 1001 (BR, isotypus P!).

Sida Xavieri Monteiro, Anais Soc. Bot. Brasil, XIX Congresso Nacional de Botânica, Fortaleza [Ceará], 1968. Typus: Brasil, Paraíba, João Pessoa, Tambaúzinho, 4-X-1941, Xavier s.n. (Laboratorio de Fibras 342) (holotypus RBR!).

Sida Martiana A.St.-Hil. var. viscosissima A.St.-Hil., Fl. Bras. mer. 1: 187. 1827. Typus: Brasil, Minas Gerais, Serra d'Ouro branco, haud longe ab urbe Villa Rica [Ouro Preto], [Saint-Hilaire s.n.] (holotypus P!).

Subarbusto viscoso, 0,50-2 m de altura, con ramas apoyantes. Tallo con indumento formado por pelos glandulares pequeños, abundantes y pelos simples erectos hasta $3 \mathrm{~mm}$ long. Hojas espiraladas. Estípulas lineares, 1-2 mm long., pilosas, tempranamente caducas. Lámina ovada, base cordada y ápice agudo, margen crenado-aserrado desde la base, hasta $4 \mathrm{~cm}$ long. x 2,5 cm lat., haz con pelos glandulares simples muy pequeños y pocos pelos estrellados sobre los nervios, envés con pelos estrellados esparcidos y algunos pelos glandulares, los dientes del margen con un pelo apical 1 $\mathrm{mm}$ long. Flores axilares solitarias, largamente pediceladas; de la axila nace una ramita florífera, con hojas pequeñas. Pedicelos hasta $45 \mathrm{~mm}$ long., articulado hacia el tercio superior, con indumento similar al del tallo. Cáliz 5-7 mm long., lóbulos triangulares 3-4 mm long. x 2-3 mm lat., margen de los lóbulos y nervios principales verde oscuro, cara externa con pelos glandulares en toda la superficie y pelos simples $1 \mathrm{~mm}$ long. en el margen de los lóbulos y sobre los nervios principales. Corola amarilla, pétalos un poco más largos que el cáliz, uña glabra o con pocos pelos, ápice con pelos hialinos muy pequeños. Tubo estaminal breve, glabro o con pocos pelos simples, hialinos. Ovario 5-carpelar. Mericarpos redondeados, múticos, glabros, $2 \mathrm{~mm}$ long. $\mathrm{x}$ $1,5 \mathrm{~mm}$ lat., dorso liso, paredes laterales frágiles. Semilla glabra. Cromosomas $2 n=28$.

Distribución geográfica: Vive en el centro de Brasil desde Paraíba hasta Minas Gerais y hacia el oeste hasta Goiás, Mato Grosso y Mato Grosso do Sul. También fue coleccionada en Bolivia en el departamento de Santa Cruz.

Etimología: Nombre dedicado a Bernard Luschnath, Jardinero del Jardín Botánico de Río de Janeiro, quién en 1835-37 coleccionó plantas en el estado de Bahía.

Material adicional estudiado: BOLIVIA. Santa Cruz: Prov. Ñuflo de Chavez, Concepción, 30IV-1977, Krapovickas \& Schinini 32031 (CTES). BRASIL. Bahia: Cruz das Almas, VIII-1950, Pinto 50-25 (RBR); Ilheos, VII-VIII-1822, Riedel s.n. (P); Sta. Cruz de Cabrália, 16-IX-1971, T. S. Santos 1945 (CTES); Porto Seguro, 4-IX-1961, Duarte 6091 (CTES, HB, RB). Distrito Federal: rio São Bartolomeu, 22-IV-1965, Heringer 10363 (CTES, UB). Espirito Santo: BR-262, Rio Jucu (Mun. Viana), 8-VI-2003, Hatschbach \& al. 75007 (CTES, MBM).Goiás: Goiatuba, 5-IV1961, Gregory \& al.10140 (CTES, LIL); entre Morrinhos y Caldas Novas, 6-IV-1961, Gregory \& al. 10151 (CTES, LIL); entre Niquelandia y Macedo, 11-IV-1961, Gregory \& al. 10231 (CTES, LIL); Formosa, rio Tiquiri, 25-V-1967, Heringer 11442 (CTES, UB); Luziana, 11-VI-1975, Heringer 14662 (CTES, UB); Mandassaia (Mun. Campos Belos), 12-V-2000, Hatschbach \& al. 70965 (CTES, MBM); Serra Geral de Goiás (Mun. São Domingos), 700 m, 13-V-2000, Hatschbach \& al. 71038 (CTES, MBM). Mato Grosso: $82 \mathrm{~km} \mathrm{~S} \mathrm{de}$ Volhena (Mun. Vila Bela), 21-V-1985, Krapovickas \& al. 40152 (C, CEN, CTES); Serra do Roncador, $12^{\circ} 51^{\prime} \mathrm{S}-51^{\circ} 45^{\prime} \mathrm{W}$, Gottsberger 14 - 
28568 (CTES). Mato Grosso do Sul: estr. Campo Grande-Rochedo, 12-VII-1969, Hatschbach 21839 (CTES, MBM); Fda. Pedra (Mun. Bataguaçu), 13-V-1973, Hatschbach 31865 (CTES, MBM); 17 km S de Campo Grande, 3-VII1977, Krapovickas \& Schinini 32940 (CTES, MBM). Minas Gerais: BR-259, 20 km SW de Gouveia, 1300 m, 20-V-1990, Arbo \& al. 4473 (CTES, SPF); Paraopeba, 10-X-1955, Heringer 9349 (CTES, UB); BR-040, $5 \mathrm{~km}$ O do rio Tejuco (Mun. Uberlandia), 13-IV-1981, Hatschbach 43862 (CTES, MBM); BR-496, córrego Pedra Brígida (Mun. Várzea da Palma), 12-III-1995, Hatschbach \& al. 61768 (CTES, MBM); BR-496, $\mathrm{km}$ 85, rio Lavado (Mun. Lassance), 13-IV-1996, Hatschbach \& al. 64632 (CTES, MBM); BR-496, km 113 (Mun. Corinto), 13-IV-1996, Hatschbach \& al. 64645 (CTES, MBM); BR-365, km 23, Serra dos Três Irmãos (Mun. Montes Claros), 18-V2000, Hatschbach \& al. 71303 (CTES, MBM); rio Paracatú, entre Paracatú y Joao Pinheiro, 27-IV1961, Gregory \& al. 10482 (LIL).

\section{Sida Martiana A.St.-Hil.}

Fig. 2 A

Saint-Hilaire, A., Fl. Bras. mer. 1: 187. 1827. "prope urbem Villa do principe [Serro] in provincia Minas Geraes". Typus: Saint-Hilaire s.n. (holotypus P! foto F 35573, isotypus P!).

Hierba anual, viscídula, $1 \mathrm{~m}$ de alt. y ramas apoyantes. Tallo cubierto de un fieltro de pelos glandulares y estrellados muy pequeños y con pelos simples 1-2 mm long., esparcidos. Hojas espiraladas. Estípulas lineares, 1-2 mm long., pilosas, tempranamente caducas. Pecíolo hasta $2 \mathrm{~cm}$ long., con tomento similar al del tallo. Lámina ovada, cordada y de ápice agudo, margen irregularmente crenado-aserrado, haz con pelos simples $0,5-1 \mathrm{~mm}$ long., esparcidos y pocos pelos estrellados pequeños sobre los nervios, envés con pelos estrellados pequeños que dejan ver la epidermis. Flores axilares, a veces en la axila nace una ramita florífera. Pedicelo hasta $20 \mathrm{~mm}$ long, piloso como el tallo. Cáliz 6-7 mm long., lóbulos triangulares, $4 \mathrm{~mm}$ long. x $3 \mathrm{~mm}$ lat., cara externa cubierta de pelos estrellados peque- ños y pocos pelos simples $1 \mathrm{~mm}$ long., esparcidos. Pétalos salmón-rosado, poco más largos que el cáliz, uña pilosa, margen superior con pelos pequeños hialinos. Ovario 5-carpelar. Mericarpos redondeados, múticos, $2 \mathrm{~mm}$ long. $\mathrm{x} 1,8 \mathrm{~mm}$ lat., glabros o con pocos pelos breves en el ápice, dorso rugoso, paredes laterales membranáceas. Semilla glabra.

Distribución geográfica: Especie conocida hasta ahora para la Cadeia do Espinhaço, en el centro del estado de Minas Gerais, en Brasil. Fue coleccionada entre 1000 y 1380 m de altura, en campos rupestres.

Etimología: Nombre dedicado a C.F.P. von Martius (1794-1868), iniciador de la Flora brasiliensis.

Material adicional estudiado: BRASIL. Minas Gerais: Rancharia, 15 km S de Ouro Preto, 1260 m, 13-V-1990, Arbo \& al. 4009 (CTES, SPF); Serra do Cipo, 10-20 km NE de Cardeal Mota, camino a Conceição do Mato Dentro, 1050-1100 m, 16-V-1990, Arbo \& al. 4239 (CTES, SPF); Serra do Cipo, Retiro do Alto do Palacio, 25 km NE de Cardeal Mota, 1380 m, 12-II-1991, Arbo \& al. 4951 (CTES, SPF); Santa Bárbara, 8-III-1982, Hensold \& al. s.n. (CTES, SPF 22402).

\section{Sida nemorensis Mart. ex Colla}

Fig. $2 \mathrm{H}$

Martius, C.F.P. ex L. Colla, Herb, pedem. 1: 416, 1833. "Brasil at Rio del Monte". Typus: Brasil, Minas Gerais, Rio Belmonte [Jequitinhonha], 1827, Martius s. n. (holotypus TO!).

Sida tomentella Miq. var. brevicalyx K. Schum. in Mart., Fl. bras. 12(3): 309-310. 1891. "in provincia Minas Geraes prope Caldas, Regnell I n.16 (ex p.)” (holotypus P! foto F 35546!).

Sida melanocaulon Hassl., Feddes Repert. 8: 34-35. 1910. "Paraguay: Sierra de Amambay, ad ripas rivuli Estrella, flor et fruct. mens. Mart.; Hassler no. 10294, leg. Rojas" (holotypus G! foto F 23778!, isotypi BAF!, $\mathrm{P}$ !). 
Sida margaritensis Hassl., Feddes Repert. 12: 266-267. 1913. "Paraguay: Ad margines silvarum in rupibus calcareis pr. Cerro Margarita, flor. et fruct. mens. Mart.; Hassler no. 11065” (holotypus G!, isotypus BM!).

Subarbusto erecto, 0,50-1,80 m alt. Tallo a veces violáceo, con pelos glandulares, pelos estrellados y con frecuencia con largas setas simples 1-2 mm long. Hojas espiraladas. Estípulas 3-8 mm long., lineares, pilosas, más o menos persistentes. Pecíolo 1-4 cm long., con tomento similar al del tallo. Lámina ovada a ovado-lanceolada, de base acorazonada y ápice agudo, margen crenado-aserrado, haz con pelos estrellados y envés con pelos estrellados algo mayores. Flores brevemente pediceladas a subsésiles, en glomérulos, axilares, o en breves ramas o agrupados en espigas terminales. Cáliz 5-7 mm long., lóbulos triangulares, 3-4 mm long. x 2 mm lat., cara externa con pelos glandulares pequeños, muy ralos, y largos pelos simples sobre los 5 nervios principales y en el margen de los lóbulos. Pétalos amarillos, uña con pelos. Tubo estaminal con pelos simples, hialinos. Ovario 5carpelar. Mericarpos trígonos, 2,5-3 mm long x 1,5 mm lat., con dos aristas apicales breves, 0,5-1,5 mm long., caras laterales reticuladas, tenaces, ápice algo piloso. Cromosomas $2 \mathrm{n}=16$.

Distribución geográfica: Vive en el nordeste de Argentina, Bolivia, Brasil y Paraguay. tín).

Etimología: nemorensis= del bosque (la-

Material seleccionado estudiado: ARGENTINA. Corrientes: Dep. Curuzú Cuatiá, Perugorría, 23-III-1967, Pedersen 8118 (C, CTES); Dep. Empedrado, $13 \mathrm{~km} \mathrm{~N}$ de San Lorenzo, 6-II-1973, Quarín \& al. 859 (CORD, CTES, SI); Dep. San Luis del Palmar, Lomas de Galarza, 20-II-1980, Carnevali 4274 (CTES); Dep. Saladas, 4 Bocas, 27-III-1976, Schinini \& Martínez Crovetto 12816 (CTES); Dep. San Martín, Yapeyú, 12-II-1979, Schinini \& al. 17006 (CTES). Misiones: Dep. Cande- laria, La Pastora, 220 m, 11-VII-1946, Montes 2413 (CTES, LIL); Dep. Eldorado, Eldorado, 10-III-1960, Keller 160 (CTES); Dep. Iguazú, Isla San Martín, 8-VIII-1991, Vanni \& al. 2793 (CTES); Dep. San Ignacio, San Ignacio, 210 m, 14-III-1951, Montes 15133 (CTES, SI); Dep. San Pedro, Laharrague, 175 m, 25-VI-1951, Montes 15425 (CTES, SI). Salta: Dep. Orán, Vado Hondo, 360 m, 19IV-1980, Legname \& al. 6909 (LIL). BOLIVIA. Santa Cruz: Prov. Ichilo, Buena Vista, 19-V-1991, Krapovickas \& Fortunato 43923 (BAB, C, CTES, LPB, USZ). BRASIL. Distrito Federal: Bacia do rio São Bartolomeu, 22-V-1980, Heringer \& al. 4870 (CTES, IBGE). Goiás: Formosa, rio Tiquiri, 18-IV1967, Heringer 11418 (CTES, UB); Piranhas, 700 m, 22-VI-1966, Irwin \& al. 17587 (CTES, NY, UB); Lageado (Mun. Cristalina), 12-IV1981, Hatschbach 43835 (CTES, MBM); JK (Mun. Formosa), 590 m, 15-IV-1983, Krapovickas \& al. 38829 (CEN, CTES). Mato Grosso: Jauru, 7-V-1995, Hatschbach \& al. 62428 (CTES, MBM). Minas Gerais: Paraopeba, 10-IV-1958, Heringer 6388 (CTES, HB, UB). Paraná: rio Capivara (Mun. Palmeira), 8-III-1984, Hatschbach 47582 (CTES, MBM); Salto de Caxias (Mun. Capitão Leônidas Marques), 2-IX-1999, Silva \& al. 3041 (CTES, MBM); Loreville, Campo das Pedras, (Mun. Londrina); 29-IX-1970, Hatschbach 24861 (CTES, MBM); Faxinal (Mun. Ivai), 15III-1972, Hatschbach 29309 (CTES, MBM). Rio de Janeiro: Santo Antonio de Pádua, Aperibé, 29-IV-1981, Carauta 3782 (CTES, GUA). Santa Catarina: Laguna, 24-I-1984, Krapovickas \& Cristóbal 39388 (C, CTES, HAS, MBM). PARAGUAY. río AguarayGuazú, V-1921, Rojas 3630 (AS, CTES). Cordillera: Tobaty, 22-III-1975, Schinini 10901 (CTES, FCQ, G). Guairá: Iturbe, 9-VI-1952, Montes 15764 (CTES, LIL).

Obs. El tipo de Sida margaritensis (G) tiene el cáliz con mayor cantidad de pelos estrellados hirsutos más o menos cortos, pero también tiene las otras dos clases de pelos: glandulares simples y pelos simples, largos sobre los nervios principales. Las tres clases de pelos están presentes en los tallos. 
17. Sida pindapoyensis Krapov., sp. nov.

Fig. 4

Suffrutex $1 \mathrm{~m}$ altus rufescentibus. Caulibus indumento triplici, pilis stellatis dense instructis, glandularis et simplicibus. Folia ovata, cordata, acuta, supra et infra dense stellato-hirsuta. Floribus 1-2 axillaribus, pedicellis 2-6 mm longis. Calyx 4-5 mm longis. Carpidiis 5 trigonis, 2,5 mm longis, submuticis.

Typus: Argentina. Misiones: Dep. Capital, Ruta 1, ayo. Pindapoy, $20 \mathrm{~km}$ NW de San José, erecta, \pm $1 \mathrm{~m}$ alt., 8-III-1953, A. Krapovickas 7935 (holotypus CTES, isotypi LIL, RBR, SI).

Subarbusto erecto, ramificado, ca. $1 \mathrm{~m}$ alt. Toda la planta de color cobrizo. Tallo cubierto de una capa enmarañada de pelos estrellados 1-2 mm long. y glandulares diminutos, abundantes, en la base de la planta sólo perduran algunos pelos simples. Hojas alternas. Estípulas lineares, hirsutas, $2 \mathrm{~mm}$ long. Pecíolo 10-20 mm long., con tomento similar al del tallo. Lámina oval, base acorazonada, ápice agudo, 20-40 mm long. x 14-25 mm lat., margen crenado-aserrado, ambas caras hirsutas, con pelos estrellados ca. $1 \mathrm{~mm}$ long. Flores una o dos por axila en el extremo de las ramas. Pedicelos 2-6 mm long., articulados, hirsutos, Cáliz 4-5 mm long., lóbulos triangulares 2-3 mm long. x 2-3 mm lat.; caras laterales subglabras, con pelos glandulares breves y con pelos estrellados 1-2 mm long. sobre los nervios principales y márgenes de los lóbulos, cara interna de los lóbulos con algunos pelos simples adpresos, esparcidos y algo mayores sobre el nervio medio. Corola amarilla, pétalos $3 \mathrm{~mm}$ long., uña glabra. Tubo estaminal 1-2 mm long., con pelos simples, hialinos. Ovario con 5 carpelos. Mericarpos trígonos, glabros, 2,5 mm long., caras laterales $1 \mathrm{~mm}$ lat. y cara dorsal $1,5 \mathrm{~mm}$ lat., reticuladas, tenaces, ápice con dos aristas apicales muy breves. Cromosomas $2 \mathrm{n}=32$.

Distribución geográfica: Conocida sólo de la localidad tipo.

Etimología: Nombre derivado del arroyo
Pindapoy situado en el SW de la provincia argentina de Misiones.

Paratypus: ARGENTINA. Misiones: Dep. Capital, ruta 1, ayo. Pindapoy, $20 \mathrm{~km}$ NW de San José, 8-III-1953, Krapovickas 7933 (CTES, RBR).

\section{Sida rufescens A.St.-Hil.}

Fig. 2 D

Saint-Hilaire, A., Fl. Bras. mer. 1: 185. 1827. "In campis petrosis propè vicum Formigas [Montes Claros], in parte occidentali desertique provinciae Minas Geraes”. Saint-Hilaire s. $n$. (holotypus P!).

Sida urens L. var. rufescens (A. St.-Hil.) Baker f., J. Bot. 30: 294. 1892.

Sida pseudo-urens Baker f., J. Bot. 30: 294. 1892. "Peru. Tarapoto, Mathews, No. 1552" (lectotypus BM!).

Sida urens L. var. aurea Hassl., Repert. Spec. Nov. Regni Veg. 12: 266. 1913. "Paraguay. Inter rupes calcareas denudatas pr. Cerro Margarita, fl. et fr. mens. Mart. Hassler no. 11037" (holotypus $\mathrm{G}$, isotypi $\mathrm{P} !, \mathrm{UC} !)$.

Sida urens L. var. aurea Hassl. f. Warmingiana Monteiro, O genero Sida: 38. 1936. "Minas Geraes: Morro das Pedras, Bello Horizonte (fl.), 30-V-933, Jard. Bot. de B. Hor. n. 7.948”.

Planta 20-60 cm alt., con ramas extendidas, con frecuencia apoyantes. Toda la planta cubierta de pelos estrellados 1-1,5 mm long., cobrizos. Tallos hirsutos. Estípulas lineares, 2-4 mm long., pilosas. Pecíolo 5-35 mm long., hirsuto. Lámina ovada, base acorazonada, ápice agudo, margen crenado-aserrado, ambas caras con pelos estrellados 1-1,5 mm long. Flores en glomérulos axilares. Pedicelo muy breve, hirsuto. Cáliz $6 \mathrm{~mm}$ long., lóbulos triangulares 2,5 mm long. x $3 \mathrm{~mm}$ lat., margen y nervios principales más oscuros, y con pelos estrellados 0,5-1 mm long.; cara interna de los lóbulos con pelos simples adpresos hacia el ápice. Corola amarilla, pétalos $5 \mathrm{~mm}$ long., uña con pelos en el margen. Tubo estaminal 3 $\mathrm{mm}$ long., con pelos hialinos, simples y algunos estrellados o de dos ramas, hacia la base. Mericarpos $2 \mathrm{~mm}$ long. x $1 \mathrm{~mm}$ lat., con una red muy fina, múticos, glabros. Semilla glabra. 


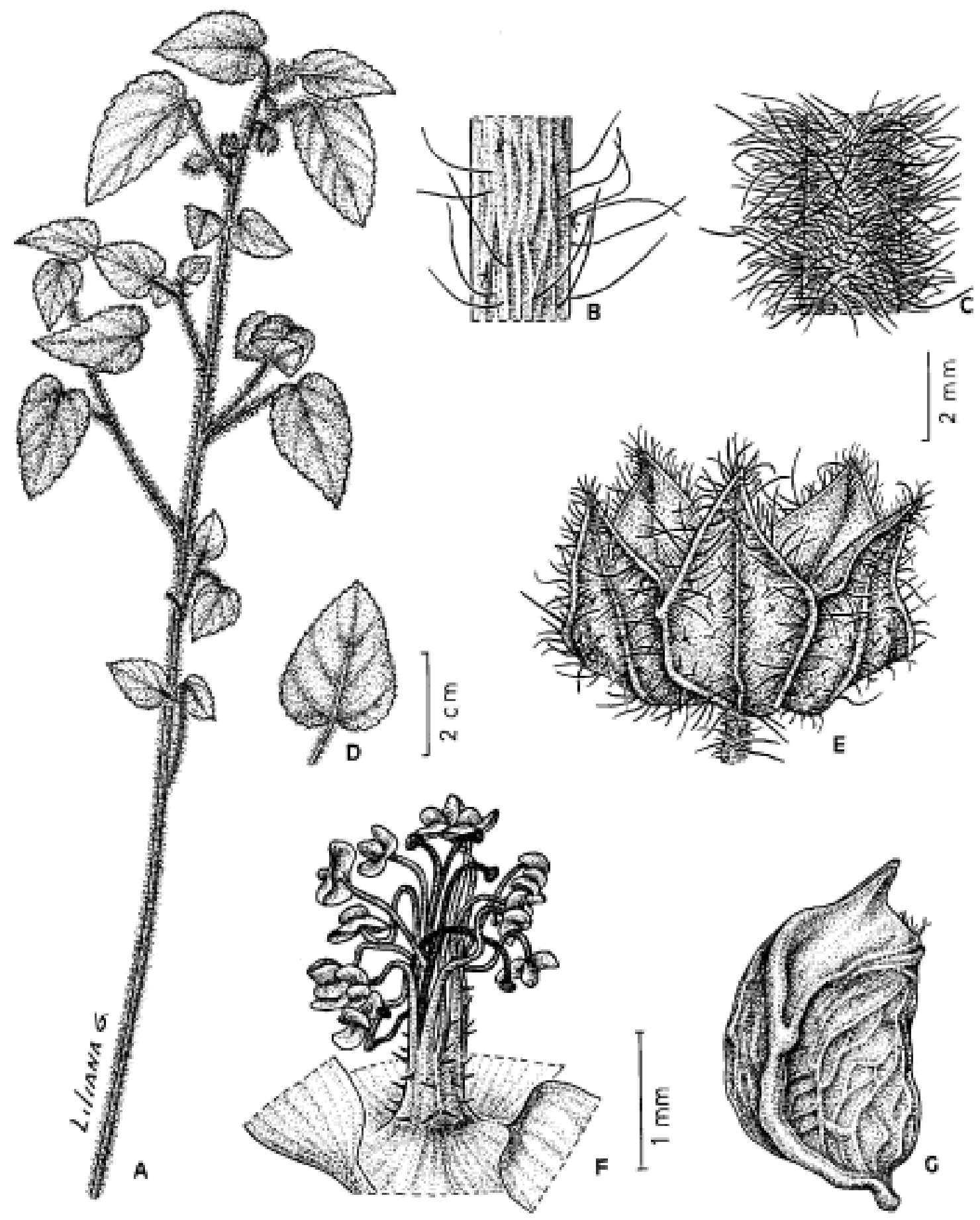

Fig. 4. Sida pindapoyensis. A: rama. B: tallo adulto. C: tallo joven. D: hoja. E: cáliz. F: androceo y gineceo. G: mericarpo (A-G, Krapovickas 7933). 
Distribución geográfica: Vive en Bolivia, Brasil, Paraguay y Perú.

Etimología: El nombre rufescens alude al color rojizo de toda la planta.

Material adicional estudiado: BOLIVIA. Santa Cruz: Santa Cruz, 22 km hacia Abapó (Sud), 500 m, 14-III-1981, Beck 6504 (CTES,LPB); prov. Ichilo, Buenavista, 4-V-1916, Steinbach s.n. (BA 64703, CTES); prov. Velazco, San Ignacio, 370 m, 5-V-1977, Krapovickas \& Schinini 32483 (CTES); prov. Ñuflo de Chavez, Concepción, 29IV-1977, Krapovickas \& Schinini 31979 (CTES); 3 km S de Ascensión de Guarayos, 250 m, 27-IV1977, Krapovickas \& Schinini 31839 (CTES); prov. Sandoval, San Matías, 170 m, 17-IV-1980, Krapovickas \& Schinini 36163 (CTES, MICH). BRASIL. Bahia: Barreiras, 460 m, 30-III-1983, Krapovickas \& al. 38699 (CEN, CTES, HAS, UC). Goiás: Alvorada (180 km NE de Formosa), 19-IV-1961, Gregory \& al. 10308 (CTES, LIL); 3 km S of São João da Aliança, 850 m, 15-III-1971, Irwin \& al. 31797 (CTES, NY, UB). Mato Grosso: Mun. Poconé, 104 km E de Cáceres, 17V-1985, Krapovickas \& al. 40107 (CEN, CTES). Mato Grosso do Sul: Entroncamento (Pto. 15 Nov.-Rio Brilhante-Campo Grande), 1-III-1959, Gregory \& al. 9802 (CTES, LIL); 8 km S de Entroncamento (estrada Campo Grande-Rio Brilhante), 11-V-1961, Gregory \& al. 10553 (CTES, LIL); Mun. Corumbá, Faz. Ipanema, Nhecolandia, 141 m, 30-X-1984, Pott 1634 (CPAP, CTES). Minas Gerais: Ituiutaba, 4-IV1961, Gregory \& al. 10118 (CTES, LIL); rio das Velhas, camino a Diamantina, 29-IV-1961, Gregory \& al. 10501 (LIL). PARAGUAY. Amambay: $5 \mathrm{~km} \mathrm{~N}$ del río Aquidabán, camino a Bella Vista, 16-V-1974, Schinini 9049 (CTES); 14 km SE de Bella Vista, 24-VI-1977, Krapovickas y Schinini 32628 (CTES). Concepción: San Salvador (Alto Paraguay), III-1917, Rojas 2591 (AS); Rancho Esperanza, potrero P1, 12-VII-1991, Degen 1994 (CTES, FCQ). San Pedro: Estancia Cororoi, ruta a Yby Yau, III-1994, Soria 6484 (CTES, FCQ). Paraguarí: Cerro Patony, 4-IV1885, Kurtz 240 (CORD, LIL); Cerro Pelado, prés de Paraguarí, 5-IV-1883, Balansa 4382 (P); Caazapa, Tavai, camino a los Mby’a, 5-VIII-1989, Soria 4001 (CTES, FCQ).

\section{Sida rupicola Hassl.}

Fig. $2 \mathrm{~N}$

Hassler, E., Feddes Repert. Nov. Sp. Regni Veg. 12: 264-265. 1913. Typus: Paraguay, inter rupes denudatus pr. Bellavista, fl- et fr. mens Febr. Hassler 10990 (holotypus G!, isotypi $\mathrm{B} \dagger$ foto $\mathrm{F}$ 9391!, BAF!, BM!, CTES!, K!, P!).

Sida rupicola var. grandiflora Hassl., ibid: 265266. 1913. Typus: Paraguay, In rupestribus in colle "Cerro Margarita”, fl. et fr. mens Mart. Hassler 11041 (holotypus G!, isotypi BAF!, BM!, CTES!, MPU!, NY!, UC!).

Iconografía: Rodrigo, 1944, figs. 26 y 27' (sub S. piauhyensis).

Hierba erecta, 0,50-1,50 m alt. Tallo con pelos glandulares densos y pelos simples 1-2 $\mathrm{mm}$ long., esparcidos. Estípulas lineares, 2$2,5 \mathrm{~mm}$ long., erectas, pilosas, caducas. Pecíolo 1-4 cm long. más breve que la lámina. Lámina 4-9 cm long. x 3,5-6 cm lat., ovada a ovado-lanceolada, base cordada y ápice agudo, a veces subtriloba, margen crenado, haz con pelos simples y algunos pelos estrellados sobre los nervios, envés con pelos estrellados que dejan ver la epidermis. Flores axilares solitarias. Pedicelo 15-30 mm long., articulado en el tercio superior, con pelos glandulares y también pelos simples breves, especialmente por encima de la articulación. Cáliz campanulado, amarillo-verdoso, con el margen y los nervios verde oscuro, 4-6 mm long., lóbulos triangulares, 3-4 mm long. x 2,5-3 mm lat., cara externa con pelos glandulares y algunos pelos estrellados pequeños, margen de los lóbulos con pelos simples o estrellados mayores, erectos, cara interna glabra salvo una línea de pelos simples adpresos en el nervio medio de los lóbulos. Corola amarilla, pétalos $6 \mathrm{~mm}$ long. x $5 \mathrm{~mm}$ lat., uña glabra. Tubo estaminal $4 \mathrm{~mm}$ long., con pelos simples, hialinos. Mericarpos 5, trígonos, 2,5-3 mm long., con las dos caras laterales y la dorsal reticuladas, consistentes, con pocos pelos simples adpresos en el ápice y dos aristas apicales 0,5-1 mm long. con pelos antrorsos. Semilla glabra. 
Distribución geográfica: Vive en el nordeste de Argentina, Bolivia, Brasil y Paraguay.

Etimología: Que crece sobre rocas.

Material seleccionado estudiado: ARGENTINA. Chaco: Dep. $1^{\circ}$ de Mayo, Colonia Benítez, II1933, Schulz 837 (CTES, LP). Corrientes: Dep. Capital, Perichón, 29-IX-1974, Krapovickas \& al. 26474 (CTES, G, UC). Dep. San Cosme, San Cosme, 21-XII-1959, Pedersen 5311 (C, CTES); Ensenada Grande, 26-IV-1964, Krapovickas \& Cristóbal 11388 (CTES). Formosa: Dep. Formosa, ruta 81, km 1245, camino Formosa a Pirané, 65 m, 20-IX-1981, Legname \& al. 8530 (LIL). BOLIVIA. Cochabamba: Prov. Cercado, Estación Experimental La Tamborada, 23-II-1950, Krapovickas 6976 (CTES, LIL, LPB, SI). La Paz: Prov. Murillo, Calacoto, 3100 m, 9-IV-1983, Beck 7986 (CTES, LPB). Santa Cruz: Buena Vista, $450 \mathrm{~m}$, IV-1915, Steinbach 1246 (LIL). Prov. Sandoval, San Matías, 170 m, 18-IV-1980, Krapovickas \& Schinini 36220 (CTES), Prov. Ñuflo de Chávez, Concepción, 30-IV-1977, Krapovickas \& Schinini 32030 (CTES, LPB). BRASIL. Bahia: $20 \mathrm{~km} \mathrm{~S} \mathrm{de}$ Ibotirama, 19-III-1982, Krapovickas \& al. 37906 (CEN, CTES). Mato Grosso do Sul: Corumbá, 27-III-1959, Gregory \& al. 9988 (CTES, LIL); Guaicurus, 17-V-2002, Hatschbach \& al. 73068 (CTES, MBM); 51 km O de Miranda, 13-II-1993, Hatschbach \& al. 59027 (CTES, MBM). Paraná: Adrianopolis, Rio Ribeira, 21-II-1978, Hatschbach \& Lourteig 41041 (CTES, MBM). PARAGUAY. Alto Paraguay: Cerro León, 30-IX-1979, Schinini \& Bordas 17852 (CTES); Cerro León, 8-VIII1983, Hahn 1573 (CTES, MO, PY). Amambay: Bella Vista, rio Apa, 25-VIII-1980, Schinini \& Bordas 20633 (CTES). Central: Carapeguá, VI1919, Rojas 3525 (AS, CTES). Cordillera: San Bernardino, IX-1916, Rojas 1221 (AS, CTES). Paraguarí: Cerro Palacios, 31-V-1988, Soria 2251 (CTES, FCQ). Presidente Hayes: Monte Lindo, 6-XII-1992, Krapovickas \& Cristóbal 44182 (CTES).

\section{Sida Schininii Krapov., sp. nov.}

Fig. 5

Suffrutex erectus. Caulibus glandulosus et pilis
2-2,5 mm longis indutis. Lamina ovata, acuta basi cordata supra pilis simplicibus vestita, infra pilis stellatis. Floribus axillaribus solitarii. Pedicellus 20-35 mm longus. Calyx $5 \mathrm{~mm}$ longis. Petalis 6 $\mathrm{mm}$ longis. Carpidiis rotundatis, apiculi $0,5 \mathrm{~mm}$ longis.

Typus: Bolivia, Santa Cruz, Prov. Sandoval, San Matías, "La Piscina”, límite internacional con Mato Grosso, 58²6'W, $16^{\circ} 21^{\prime}$ 'S, 170 m, 18-IV1980, A. Krapovickas \& A. Schinini 36223 (holotypus LPB, isotypus CTES).

Subarbusto erecto, $1 \mathrm{~m}$ alt. Tallo cubierto con pelos glandulares breves, no muy densos y pelos simples 2-2,5 mm long., esparcidos. Estípulas lineares, 1-2 mm long., pilosas, caducas. Pecíolo 1-3,5 cm long., con tomento similar al del tallo. Lámina ovada, base acorazonada, ápice agudo, margen crenadoaserrado desde la base, hasta $6,5 \mathrm{~cm}$ long. $\mathrm{x}$ 3,5 cm lat.; haz con pelos simples menores de $0,5 \mathrm{~mm}$ long., esparcidos, envés con pelos estrellados más abundantes sobre los nervios, dientes a menudo con un pelo 0,5-1 mm long., en el ápice. Flores axilares, solitarias y por decrecer el tamaño de las hojas, en panículas terminales; a veces en la axila de una flor una rama florífera breve. Pedicelo 20-35 mm long., articulado ca. 0,5 cm por debajo del cáliz; tomento similar al del tallo. Cáliz $5 \mathrm{~mm}$ long., lóbulos triangulares, $3 \mathrm{~mm}$ long. x 2,5 mm lat., margen de los lóbulos verde más oscuro, cara externa con pelos glandulares breves, esparcidos y pelos simples, 0,5-1 mm long. en el margen de los lóbulos y en los nervios principales, cara interna con pelos diminutos hacia el ápice de los lóbulos. Corola amarilla, pétalos $6 \mathrm{~mm}$ long., margen superior con pelos pequeños, hialinos. Tubo estaminal $2 \mathrm{~mm}$ long. Ovario 5-carpelar. Mericarpos redondeados, $2 \mathrm{~mm}$ long. x 1,8 mm lat., brevemente apiculados, apículos 0,2 mm long., paredes laterales frágiles, dorso liso, ápice y dorso con pelos simples. Cromosomas 2n=14.

Distribución geográfica: Vive en Bolivia, en el departamento de Santa Cruz, en la región chiquitana y también en el Pantanal de Mato Grosso do Sul. 
A. Krapovickas, Sida secc. Nelavaga (Malvaceae, Malveae)

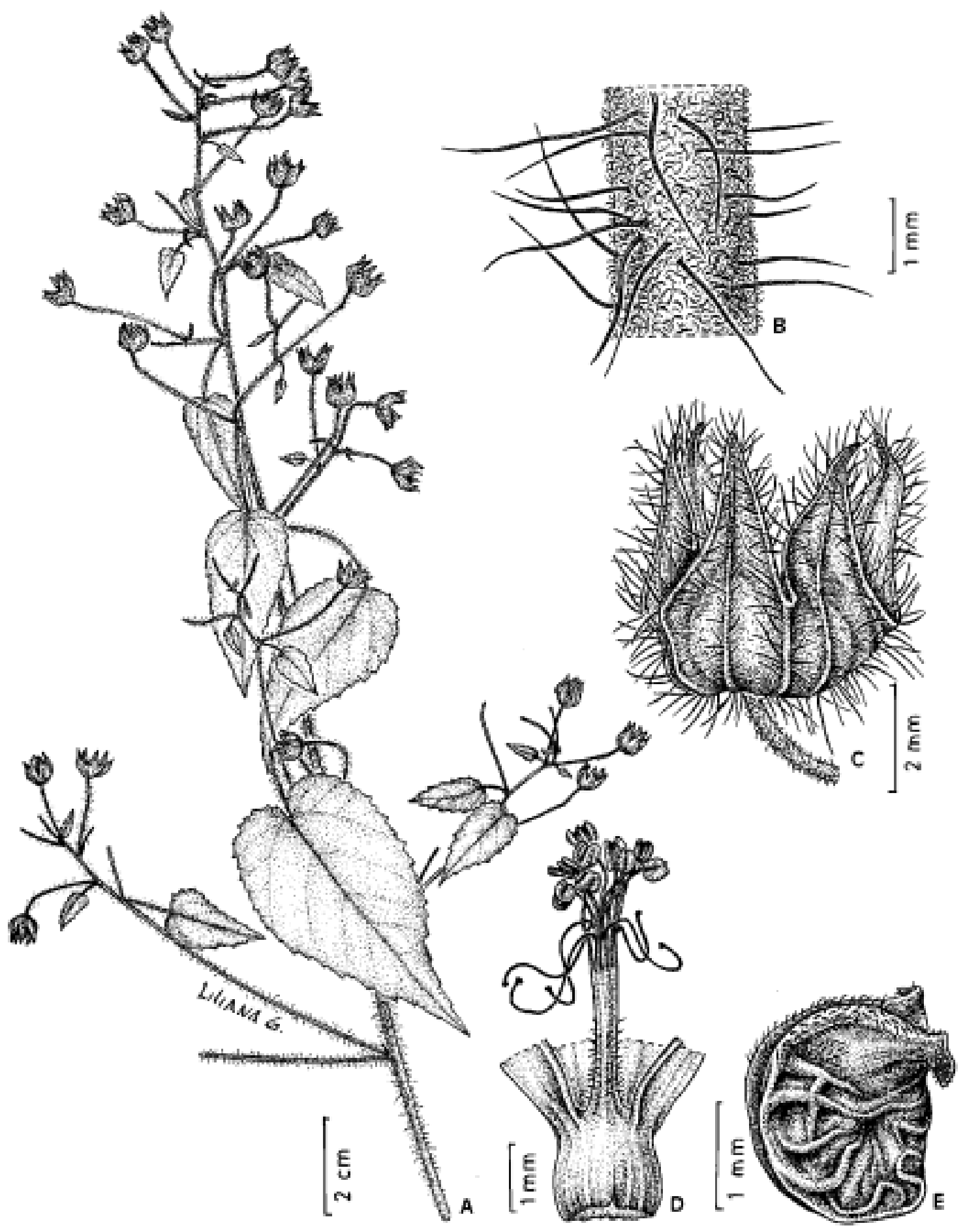

Fig. 5. Sida Schininii. A: rama. B: tallo. C: cáliz. D: androceo y gineceo. E: mericarpo (A-E, Krapovickas \& Schinini 36223). 
Nombre vernáculo: "malva tapora" (Krapovickas 32250).

Etimología: Esta especie está dedicada al Sr. Aurelio Schinini, del Instituto de Botánica del Nordeste, que participó en la colección del material tipo.

Paratypi: BOLIVIA. Santa Cruz: Prov. Chiquitos, Santiago, 13-II-1958, Krapovickas 9424 (LIL). Prov. Nuflo de Chavez, Embocada del Carmen, 40 km SSW de Concepción, 550 m, 2-V1977, Krapovickas \& Schinini 32950 (CTES); 30 km S de Concepción, 500 m, 1-V-1977, Krapovickas \& Schinini 32099 (CTES); 29 km S de Concepción, 537 m, 5-IV-2004, Seijo \& al. 3226 (CTES). Prov. Velazco, San Ignacio, 370 m, 5-V1977, Krapovickas \& Schinini 32250 (CTES, SI); $10 \mathrm{~km}$ E de San Ignacio, 6-V-1977, Krapovickas \& Schinini 32267 (CTES, LPB). BRASIL. Mato Grosso do Sul: Mun. Miranda, Estancia Caiman, 75 m, 4-IV-1998, Pott \& al. 7930 (CPAP, CTES)

\section{Sida Schumanniana Krapov., sp. nov.}

Fig. 6

Sida urens L. var. grandiflora K. Schum. in Mart., Fl. bras. 12(3): 307. 1892. "in Peruvia: Pavon" [non Sida grandiflora (Paxton) Walp. 1848, = Callirhoe papaver (Cav.) A. Gray].

Herba perennis basi lignescens caulibus procumbentes usque ad $2,50 \mathrm{~m}$ longis eglandulosis, pilis $2 \mathrm{~mm}$ longis hispidis vel glabrescens. Folia ovata longe acuminata basi cordata. Inflorescentiis axillaribus et terminalibus congestis; floribus sessilibus. Calyx 8-12 mm longis. Carpidiis 5 trigonis 2,5 mm longis, $1 \mathrm{~mm}$ latis, muticis vel submuticis.

Typus: Argentina. Salta: Dep. Orán, Orán, 15VII-1962, Krapovickas \& Legname 4509 (holotypus CTES, isotypus LIL).

Planta postrada o apoyante, con ramas hasta 2,50 m long. Tallo hirsuto, pelos simples 2 $\mathrm{mm}$ long., a veces glabro. Estípulas lineares, 2-5 mm long., hirsutas, caducas. Pecíolo 2-4 cm long., glabro, con una línea longitudinal de pelos 0,5-1 mm long. Lámina ovada, base acorazonada, ápice agudo, hasta $10 \mathrm{~cm}$ long. $\mathrm{x}$ $6 \mathrm{~cm}$ lat., margen crenado-aserrado, haz con pelos simples 0,5-1 mm long., adpresos, esparcidos, envés con algunos pelos estrellados, con frecuencia ambas caras glabras o subglabras. Flores en glomérulos axilares o en densas espigas apicales. Pedicelo muy breve. Cáliz 8-12 mm long., lóbulos triangulares, 5-7 $\mathrm{mm}$ long. $\mathrm{x} 5 \mathrm{~mm}$ lat., margen de los lóbulos y nervios principales verde oscuro y con pelos simples y estrellados ca. $2 \mathrm{~mm}$ long.; a veces pocos pelos glandulares presentes. Pétalos 9$11 \mathrm{~mm}$ long. x $6 \mathrm{~mm}$ lat., amarillos, uña con pelos simples en el margen, a lo largo de $2 \mathrm{~mm}$ basales. Tubo estaminal $6 \mathrm{~mm}$ long., glabro, raro con pelos simples hialinos. Estigmas 5, Ovario con 5 carpelos. Mericarpos trígonos, 2,5 mm long., caras $1 \mathrm{~mm}$ lat., casi lisos, con un retículo suave, múticos o con dos aristas muy breves, glabros o con pelos breves en el ápice.

Distribución geográfica: Vive en los Andes entre 200 y 2000 m de altura, desde Venezuela hasta el norte de Salta en Argentina. Crece principalmente en la selva pedemontana y en ambientes modificados. También se la coleccionó en el estado de Rio de Janeiro, Brasil.

Etimología: Nombre dedicado a Karl Schumann (1851-1904) uno de los colaboradores más prolíficos de la Flora brasiliensis de Martius y autor de gran parte de las Malváceas de esta Flora.

Paratypi: ARGENTINA. Salta: Dep. Orán, Agua Blanca, 5-VIII-1969, Legname \& Cuezzo 7115 (CTES, LIL); Vado Hondo, 6-VIII-1969, Legname \& Cuezzo 7044 (LIL); Isla de Cañas, 500 m, 17-IX-1982, Legname \& al. 8786 (LIL); río Sta. María, 1-VII-1944, Willink 110 (LIL); Santa María, 17-VII-1944, Willink 194 (CTES, LIL); río Pescado, 10-VII-1946, Borsini 582 (LIL); Aguas Blancas, río Bermejo, 1-VI-1963, Legname \& Cuezzo 4028 (CTES, LIL); entre Agua Blanca y Angosto del Pescado, ruta 19, 19-IX-1991, Guaglianone \& al. 2725 (CTES, MCNS, SI). Dep. San Martín, Porcelana, río Tarija, 3-IX-1944, Schulz 5514 (LIL); Sierra de Ramos, 20-IV-1944, Schulz \& Varela 5472 (LIL). BOLIVIA. La Paz: 


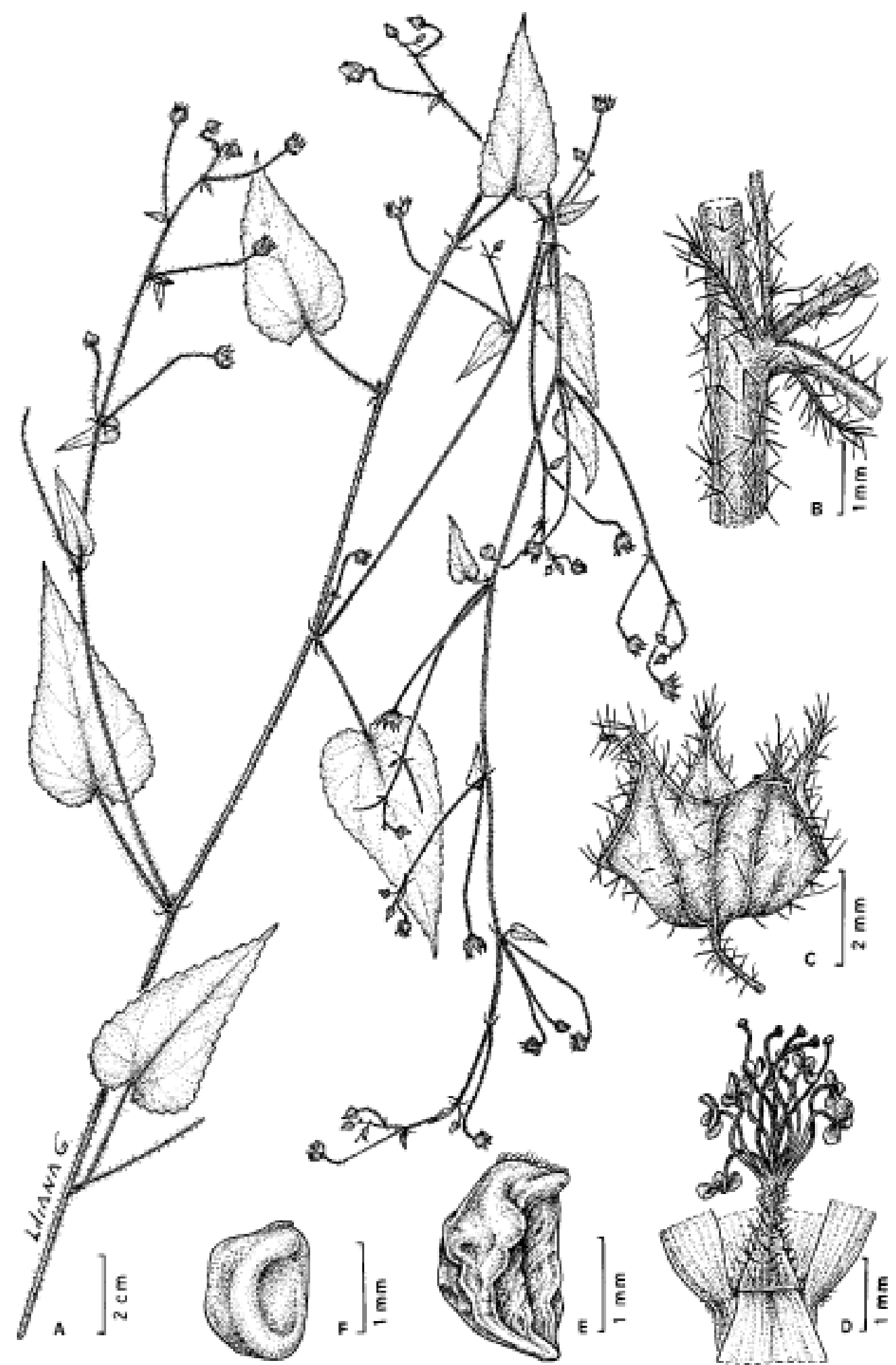

Fig. 6. Sida Schumanniana. A: rama. B: tallo. C: cáliz. D: androceo y gineceo. E: mericarpo (A-D, Krapovickas \& Legname 4509. E, Solomon \& Nee 14297). 
S. Yungas, Basin of rio Bopi, San Bartolomé (near Calisaya), 750-900 m, 1-22-VII-1939, Krukoff 10020 (LP,UC) y Krukoff 10047 (LIL, LP, UC); $3,8 \mathrm{~km}$ W of Huancané, on the road to Chuspipata, 2000 m, 29-IX-1985, Solomon \& Nee 14297 (CTES, MO); Puente Villa, 2 km del río Yamampaya, 1500 m, 2-IX-1990, Beck 17743 (CTES, LPB); Prov. Larecaja, $11 \mathrm{~km} \mathrm{~N}$ de La Aguada, 3-VIII-2003, Ferrucci \& al. 2077 (CTES, LPB); Prov. Nor Yungas, Santa Rosa, 1530 m, 5IX-1987, Vargas \& Seidel 451 (CTES, LPB). Pando: Prov. Madre de Dios, barraca Sena, río Madre de Dios, 220 m, 3-IX-1985, Moraes 453 (CTES, LPB). Santa Cruz: prov. Velasco, Estancia Flor de Oro, río Iténenz, 190 m, 13³3’s, 6100’W, 27-VII-1991, Nee 41483 (CTES, NY). Prov. Ichilo, Parque Nacional Amboro, 450 m, 22IX-1990, Nee 38869 (CTES, NY). Tarija: prov. Arce, Puente Internacional Aguas Blancas, 15VII-2003, Ferrucci \& al. 1724 (CTES, MO, SI, USZ). BRASIL. Rio de Janeiro: Bom Jardim, Hôrto Municipal, 14-VIII-1984, Carauta 4826 (CTES). COLOMBIA. Santa Marta: 18981901, Smith 718 (P, UC). Cali: Dep. Risaralda, Hacienda Los Visos, 1170 m, 448’ N, 7550’W, 28-XII-1994, Silverstone-Sopkin \& al. 7189 (CTES, CUVC); Hacienda Alejandría, $940 \mathrm{~m}$, 451'N, 7552’W, 26-I-1991, Silverstone-Sopkin \& al. 6064 (CTES, CUVC). PARAGUAY. Amambay: Sierra de Amambay, VII-1908, leg. T. Rojas, Hassler 10540 (LIL, P, SI, UC); Cerro Corá, río Aquidaban, 17-VIII-1980, Schinini \& Bordas 20231 (CTES, G). PERÚ. La Libertad: Huamachuco, Sartimbamba, 2800 m, 25-I-1952, Infantes Vera 4008 (LIL). San Martín: Prov. Mariscal Cáceres, Chauyauyacu, Cañuto, 600-700 m, 10VIII-1979, Ferreyra 19300 (CTES, LIL). Loreto: Aguaytia, 180 m, 26-VIII-1946, Woytkowski 34434 (LIL). Huánuco: entre Huánuco y Tingo María, Hda. Paty, 1700-1800 m, 22-VII-1953, Ferreyra 9350 (CTES, USM). Cuzco: Quispican, Hda. Tio Marcapata, 1200-2000 m, 14-VII-1945, Vargas C. 5196 (LIL). VENEZUELA. Lara: distr. Jiménez, Paso Angostura, represa de Yacambú, $33 \mathrm{~km}$ SE de Sanare, 941'N, 69³1'W, 500 m, 27-XII-1973, Steyermark \& Carreño Espinoza 108781 (VEN).

Obs. Excepto los ejemplares Ferrucci 2077, Krukoff 10020, Nee 41483 (Bolivia) y Ferreyra 9350 (Perú), que presentan algunos pelos simples en el tubo estaminal, el resto del material estudiado tiene dicho tubo completamente glabro.

\section{Sida urens $\mathbf{L}$.}

Fig. 2 E

Linnaeus, C., Syst. Nat. ed. 10: 1145. 1759. Typus: Browne s.n. [Jamaica] (holotypus LINN866.20! foto Rodrigo, 1944, lam. 17). Linnaeus, Amoen. acad. 5: 402, 1760.

Sida verticillata Cav., Diss. 1: 13, t. 1, fig. 12, 1785. "Rio de Janeiro; observata à D. Comm[erson]. V.S. apud D. de Jussieu” (holotypus P-JU 12275!, isotypi P!, MA! foto F 29796!).

Sida hirta urticata P.Browne, Civ. nat. hist. Jamaica: 280. 1756.

Iconografía: Fuertes Aguilar, 1995, fig. 3. Rodrigo, 1944, figs. 24 y 19' y lam. XVII.

Hierba sufruticosa, decumbente, con ramas apoyantes hasta 1-1,5 m long. Tallo con pelos glandulares y estrellados pequeños y pelos simples 1-3 mm long. Estípulas lineares, 2-5 mm long., pilosas, caducas. Pecíolo 1-5 cm long., hirsuto, con tomento similar al del tallo. Lámina ovada, base acorazonada y ápice agudo, 2-8,5 cm long. x 2-5 cm lat., margen crenado-aserrado hasta la base, ambas caras con pelos estrellados y también pelos simples antrorsos en el haz. Flores en glomérulos paucifloros axilares y en espigas en el extremo de las ramas. Pedicelos muy breves. Cáliz $6 \mathrm{~mm}$ long., lóbulos triangulares, $2 \mathrm{~mm}$ long. x $3 \mathrm{~mm}$ lat., cara externa con 5 nervios y márgenes de los lóbulos verde oscuro, cara con pelos glandulares esparcidos, margen de los lóbulos con pelos simples pequeños y setas $2 \mathrm{~mm}$ long. en los nervios y hacia el ápice de los lóbulos. Pétalos amarillos, $7 \mathrm{~mm}$ long. x $6 \mathrm{~mm}$ lat., con una escotadura apical, uña glabra o con pocos pelos. Tubo estaminal 11,5 mm long., con pelos simples. Anteras ca. 15. Estilos 5, estigmas en cabezuela. Mericarpos ca. $3 \mathrm{~mm}$ long., caras laterales $1 \mathrm{~mm}$ lat., cara dorsal 1,5 mm lat., múticos, casi lisos, de paredes frágiles, glabros o con pocos pelos breves en el ápice. Semilla glabra, con pocos 
pelos muy pequeños en el ápice. Cromosomas $2 \mathrm{n}=32$.

Distribución geográfica: Desde México y Antillas hasta el norte de Argentina y sur de Brasil, hasta los $30^{\circ}$ de latitud S. Ha sido mencionada para varios países de África tropical.

Material seleccionado estudiado: ARGENTINA. Chaco: Dep. Presidencia de la Plaza, Presidencia de la Plaza, 24-II-2004, Tressens \& Keller 6997 (CTES); Dep. $1^{\circ}$ de Mayo, Colonia Benítez, I-1932, Schulz 556 (CTES); id. 22-III-1935, Schulz 2101 (CTES); Dep. San Fernando, isla Antequera, 18-III-1967, Krapovickas \& Cristóbal 12731 (CTES). Corrientes: Dep. Capital, Riachuelo, 3-IV-1976, Schinini \& Martínez Crovetto, 12884 (CTES); Dep. Concepción, Tabay, 1-XI1965, Krapovickas \& Cristóbal 11664 (CTES); Paso Pucú, 19-II-1969, Pedersen 9029 (C, CTES); Carambola, 17-II-1983, Pedersen 13502 (C, CTES); Dep. Empedrado, El Sombrero, 9-III1950, Schwarz 10080 (CTES, LIL); Dep. General Alvear, ruta 40 y río Aguapey, 20-XI-1973, Lourteig \& al. 2839 (CTES); Dep. General Paz, General Paz (Caá Catí), 24-X-1949, Schwarz 8424 (CTES, LIL); Lomas de Vallejos, 1-I-1966, Krapovickas \& Cristóbal 11808 (CTES); Dep. Itatí, Puerto Corazón, 17-II-1983, Schinini \& Carnevali 23259 (CTES); Dep. Ituzaingó, Santa Tecla, 14-III-1946, Ibarrola 4292 (CTES, LIL); ruta 14, Centinela, 8-II-1969, Krapovickas \& Cristóbal 14808 (CTES); Isla Apipé Grande, Puerto Mora, 11-XII-1973, Krapovickas \& al. 24336 (CTES); Villa Olivari, FIPLASTO, 5-IV-1995, Tressens \& Barrett 5241 (CTES); Dep. Mburucuyá, Estancia Santa Teresa, 3-V-1964, Krapovickas \& Cristóbal 11416 (CTES); Dep. Mercedes, ruta 23 y río Miriñay, 7136, Schinini \& al. 7136 (CTES); Colonia Pellegrini, 6-III-1973, Quarín \& Schinini 1014 (CTES); Dep. Saladas, Rincón de Ambrosio, 5-II-1950, Schwarz 9568 (CTES, LIL); Dep. San Cosme, Ingenio Primer Correntino, 29-IV-1974, Benítez 164 (CTES); Paso de la Patria, 20-III-1975, Arbo \& al. 742 (CTES); Dep. San Luis del Palmar, Cerrudo Cué, 4-X-1945, Ibarrola 3390 (CTES, LIL); San Luis del Palmar, 23-I-1972, Pire \& al. 72 (CTES); Dep. San Martín, Tres Cerros, Schinini \& al. 21863 (CTES); Yapeyú, 28-I-1976, Krapovickas \& al.
28973 (CTES); Dep. San Miguel, 21 km S de Loreto, 13-VI-1974, Schinini \& González 9303 (CTES); Dep. San Roque, río Santa Lucía, 58²5'W 2284' S, 5-III-1980, Ahumada 3640 (CTES); Dep. Santo Tomé, Virasoro, Establecimiento Las Marías, 7-XII-1981, Tressens \& al. 1774 (CTES); Colonia Garabí, 19-VII-1982, Tressens \& al. 2081 (CTES); Ayo. Chimiray y ruta 40, 12-XII-1984, Tressens \& al. 2829 (CTES). Formosa: Dep. Patiño, Bartolomé de las Casas, 8-V-1969, Schulz 16976 (CTES); Dep. Pilagá, Espinillo, 7-III-1949, Morel 7322 (CTES, LIL); Buena Vista, 16-VII1997, Schinini \& al. 32651 (CTES); Dep. Pilcomayo, Sol de Mayo, 24 km SW de Laguna Blanca, 25-X-1995, Schinini \& Cuadrado 30339 (CTES); Parque Nacional Pilcomayo, 14-III-1992, Fortunato 2714 (BAB, CTES); Dep. Pirané, Corzo Cué, 15-II-1946, Morel 939 (CTES, LIL); El Colorado, IV.1977, Insfrán 1334 (CTES). Jujuy: Dep. Capital, Jujuy, 1300 m, 27-VII-1947, Krapovickas 3513 (CTES, LIL); Lozano, 7-IV-1980, Krapovickas \& Schinini 35868 (CTES); Dep. Dr. M. Belgrano, Tiraxi, 1600 m, 12-V-1998, Krapovickas \& al. 47365 (CTES); Dep. El Carmen, Perico, 11-V-1975, Krapovickas \& al. 28494 (CTES); Perico, 1180 m, 11-XI-1975, Cuezzo 11748 (CTES, LIL); Los Lapachos, 3-IV-1996, Krapovickas \& Cristóbal 46667 (CTES, CUVC, F, GH, MBM, MEXU, NY); Dep. Ledesma, Caimancito, 17-IX-1976, Cabrera \& al. 27949 (CTES, SI). Misiones: Dep. Candelaria, Santa Ana, 5-II-1947, Schwindt 92 (CTES, LIL); Dep. Eldorado, Eldorado, 10-III-2001, Keller 658 (CTES); Dep. Guaraní, Ayo. Chafariz, 28-II-1950, Schwindt 3243 (CTES, LIL); Dep. Gral. San Martín, Puerto Rico, 13-XI-1996, Vanni \& al. 3851 (CTES); Dep. Iguazú, Parque Nacional Iguazú, Ayo. Yacui, 8VIII-1995, Vanni \& al. 3395 (CTES); Dep. Dep. San Ignacio, Teyucuaré, $250 \mathrm{~m}, 12-\mathrm{V}-1955$, Montes 14793 (CTES, NY); San Ignacio, 220 m, 21III-1956, Montes 14929 (CTES, NY); Ayo. Horqueta, 14-II-1990, Honfi 61 (CTES); Dep. San Javier, Ayo. Guerrero, 6-IV-1997, Dematteis 638 (CTES); Dep. San Pedro, San Pedro, 21-IV-1950, Schwindt 4008 (CTES, LIL); Caraguatay, 26-IV1949, Montes 1596 (CTES, LIL). Salta: Dep. Capital, San Luis, 10-V-1975, Krapovickas \& al. 28462 (CTES); Dep. La Caldera, La Caldera, 10V-1975, Krapovickas \& al. 28464 (CTES); Abra de Santa Laura, ruta 9, km 1657, 6-IV-2004, Krapovickas \& al. 47892 (CTES); Dep. Gral. 
Güemes, Gral. Güemes, 700 m, 12-V-1990, Novara \& Bruno 9895 (CTES, MCNS); Dep. Orán, río Pescado, 10-VII-1946, Borsini 570 (CTES, LIL); Dep. Rosario de la Frontera, El Encón, 26-III-1977, Krapovickas \& Schinini 30575 (CTES); Dep. San Martín, Campo Durán, 29-I-1953, Krapovickas 7992 (CTES, LIL). Santa Fe: Dep. General Obligado, El Sombrerito, 4-III1986, Blanchoud 2088 (CTES). BOLIVIA. Beni: Trinidad, 14-IV-1979, Krapovickas \& Schinini 34986 (CTES, SI). Chuquisaca: Prov. Luis Calvo, El Salvador, 23-V-1992, Saravia Toledo 10945 (CTES). La Paz: Prov. Nor Yungas, Yolosa, 1280 m, 6-V-1990, Luteyn \& Dorr 13512 (CTES, NY); Coroico, 1900 m, 5-V-1991, Beck 19860 (CTES, LPB); Larecaja, Guanay, 2-VIII2003, Ferrucci \& al. 2047 (CTES, LPB). Santa Cruz: Prov. Chiquitos, Roboré, 1-IV-1959, Krapovickas 10030 (CTES, LIL, SI); Prov. Ñuflo de Cháves, Concepción, 1-V-1977, Krapovickas \& Schinini 32097 (CTES); Prov. Velasco, San Ignacio, 400 m, 29-IV-1986, Seidel \& Beck 316 (CTES, LPB). Tarija: Prov. Arce, La Mamora, 980 m, 13-III-1974, Türpe \& al. 4753 (CTES, LIL); Prov. Gran Chaco, Ipa, 30 km N de Villa Montes, 3-VI-1971, Krapovickas \& al. 19456 (CTES); Caiza, 600 m, 7-IV-1977, Krapovickas \& Schinini 30987 (CTES); Prov. O’Connor, Entre Ríos, 1450 m, 20-V-1971, Krapovickas \& al. 19025 (CTES, LPB, MO; TEX). BRASIL. Amazonas: Manaus, 26-VI-1974, Lasseign P21184 (CTES, INPA, NY). Bahia: Itabuna, 17-VIII1982, E. B. Santos 27 (CEPLAC, CTES) Itapetinga, 19-IV-1978, Mattos Silva 166 (CEPLAC, CTES) Distrito Federal: Brasília, 30-V-1979, Botelho 10 (CTES). Goiás: Piranhas, 23-V-1966, Irwin \& al. 17683 (CTES, NY). Mato Grosso do Sul: Mun. Bodoquena, Morraria do Sul, 15-V-2002, Hatschbach \& al. 72975 (CTES, MBM); Mun. Corumbá, Fazenda Acurizal, 4-IX-1987, Pott 3380 (CTES). Minas Gerais: Belo Horizonte, 3V-1999, Lombardi 2811 (BHCB, CTES); Caldas, 23-I-1980, Krapovickas \& Cristóbal 35450 (CTES); Iguatama, $750 \mathrm{~m}, 10-\mathrm{VIII}-2003$, Melo 826 (BHCB, CTES); Paraopeba, 5-V-1958, Heringer 6410 (CTES, UB); Mun. Santa Rita do Sapucaí, 7-VI-1996, Ribas 1396 (CTES, MBM). Paraná: Foz do Iguaçu, Parque Nacional, 20-IV1965, Hatschbach 12609 (CTES, MBM); Guarapuava, Canta Galo, 26-X-1968, Hatschbach 19861 (CTES, MBM); Jundiaí do Sul, Fazenda
Singela, 10-III-2001, Carneiro 1099 (CTES, MBM); Laranjeiras do Sul, río Iguaçu, Salto Osorio, 18-IV-1970, Hatschbach 24156 (CTES, MBM); Paranaguá, Saquarema, 23-V-1985, Cordeiro 44 (CTES, MBM); Ribeirão Claro, Água da Mula, 22-VI-1988, Kranz 346 (CTE, HAS); Siqueira Campos, Rib. do Veado, 28-III1974, Kummrow 475 (CTES, MBM); Tibagi, Fda. Rancho Queimado, 2-XI-1964, Hatschbach 11822 (CTES, HB, MBM). Rio de Janeiro: Rio de Janeiro, Vista Chineza, 6-V-1946, Ochioni 571 (CTES, RFA). Rio Grande do Sul: Arroio do Tigre, Barragem de Itaúba, 12-IV-1978, Bueno 649 (CTES, HAS); Dois Irmãos, rio Feitoria, 27-I-1983, Bueno \& Krapovickas 3621 (CTES, HAS); Estrela, Benfica, 5-I-1977, Bueno 257 (CTES, HAS); Porto Alegre, 18-VIII-1981, Bueno 3016 (CTES, HAS); Santo Angelo, São Miguel, 14-VI-1975, Hagelund 9263D (CTES); São Leopoldo, 28-I-1973, Krapovickas \& al. 22970 (CTES, MBM, P). Rondônia: Pimenta Bueno, 22V-1985, Krapovickas \& al. 40160 (CEN, CTES). Santa Catarina: Itajaí, 5 m, 1-III-1969, Klein 8218 (CTES, HBR); Piçarras, 19-I-1991, Krapovickas \& Cristóbal 43760 (CTES); Sombrio, 3-II-1994, Krapovickas \& Cristóbal 44740 (CTES, GH, LIL, MEXU). São Paulo: Atibaia, Gottsberger 12-10368 (CTES); São Paulo, 5-IV-1946, Joly 17335 (CTES, SPF). PARAGUAY. Alto Paraguay: Palmas Chicas, 28VI-1977, Krapovickas \& Schinini 32756 (CTES). Alto Paraná: Ea. Santa Elena, Pira Pyta, 11-X-1990, Schinini \& Caballero Marmori 27233 (CTES). Amambay: Bella Vista, 24-II-1994, Krapovickas \& Cristóbal 44988 (BH, CTES, G, MO). Caaguazú: Ayo. Yhú, 42 km S de Yhú, 10-III-2002, Schinini \& al. 36179 (CTES, PY); 20 km N de Caaguazú, 6-IV-1965, Brescia \& Marchesi 5061 (CTES, MVFA); Pastoreo, 5-II1959, Gregory \& al. 9608 (CTES, LIL). Caazapá: Tapyta, 12-II-2001, Herrera 361 (CTES). Central: Luque, 16-I-1951, Schwarz 11659 (CTES, LIL); Tavarory, 25-III-1992, Zardini 31426 (AS, CTES, MO). Concepción: Concepción, 25-II-1968, Krapovickas \& al. 14243 (BAA, CTES, FCQ); ayo. Tagatiyá-Mí, 16-III-1994, Zardini 38939 (AS, CTES, MO). Cordillera: Tobatí, 24-V-1964, Krapovickas \& Cristóbal 11460 (CTES). Guairá: Col. Independencia, 26-III-1993, Schinini \& al. 27960 (CTES); Mbocyaty, 6-VII-1992, Zardini 32441 
(CTES, FCQ, MO). Itapúa: Jesus, 7-X-1993, Krapovickas \& Cristóbal 44508 (CTES). Misiones: Santa María, 10-II-1983, Lurvey 664 (CTES); Santiago, 3-II-1988, Schinini \& Vanni 26020 (CTES). Ñeembucú: Pto. Bermejo, 13-XII-1950, Schulz 7804 (CTES). Paraguari: Acahay Massif, 20-I-1992, Zardini 29894 (CTES, MO, PY). Presidente Hayes: frente a Concepción, 28-II-1994, Krapovickas \& Cristóbal 45112 (CTES, G, MO). PERÚ. Junín: Palca, 2500 m, 23-V-1955, Krapovickas 8248 (CTES, LIL); San Ramón, 800 m, 18-VI1954, Constance \& Tovar 2325 (UC).

Obs. 1. En Corrientes las flores de Sida urens están abiertas desde las 13 hasta las 15 horas. A las 11 horas, con la corola aún no desplegada, ya se produce la dehiscencia de las anteras y se observan granos de polen en los estigmas. Durante la antesis los estilos se doblan poniendo los estigmas en contacto con las anteras de la misma flor.

Obs. 2. Gandoger (1924) divide a Sida urens L. en cuatro entidades infraespecíficas con nomenclatura binaria, una de ellas, S. urens microsp. S. boliviana Gand., es de Bolivia (Guanai, Bang 1446), las tres restantes son de Cuba. Gandoger no indica la categoría de estas entidades pero Stafleu \& Cowan (1976) las interpretan como microespecies y que en general no han sido tenidas en cuenta por la mayoría de los taxónomos y no figuran registradas en el Index kewensis. Estas microespecies no tienen diagnosis pero se podría interpretar como tal las frases de la clave en latín: "Folia tomentella 2 c. lata", lo que no es suficiente para reconocer a la microespecie S. boliviana.

\section{Sida vagans Krapov., sp. nov.}

Fig. 7

Herba prostrata, subglabra. Caule repente, radicantibus. Folia ovata cordata acuminata, usque ad $45 \mathrm{~mm}$ longa et $22 \mathrm{~mm}$ lata, subglabrata. Floribus solitariis. Pedicelli 25-30 $\mathrm{mm}$ longis. Calyx $6 \mathrm{~mm}$ longis Carpidiis 5, trigonis, submuticis, $3 \mathrm{~mm}$ longis, 1,5 $\mathrm{mm}$ latis, laevigati. Semina glabra.

Typus: Bolivia, Santa Cruz, prov. Sara, orilla de curiche en el monte de Palometillo, 17-VI1916, J. Steinbach 2337 (holotypus LIL).

Hierba rastrera, ramas hasta un metro de largo, con raíces adventicias. Tallos jóvenes con pelos estrellados muy pequeños, esparcidos, tallos adultos subglabros. Estípulas filiformes 1-2 mm long, con pelos estrellados similares a los del tallo. Pecíolo 10-20 mm long., subglabro. Lámina ovada, acorazonada, ápice agudo, hasta $45 \mathrm{~mm}$ long. x $22 \mathrm{~mm}$ lat., margen crenado-aserrado, ambas caras subglabras, con algunos pelos estrellados principalmente sobre los nervios, los pelos son algo mayores en la cara inferior. Flores axilares, solitarias, a lo largo de las ramas. Pedicelos subglabros, 25-30 mm long. Cáliz $6 \mathrm{~mm}$ long. con lóbulos $3 \mathrm{~mm}$ long. x 2,5 mm lat., subglabro, con algunos pelos estrellados pequeños en el margen; márgenes de los lóbulos más oscuros que el resto del cáliz. Carpelos 5. Mericarpos trígonos, $3 \mathrm{~mm}$ long. x $1 \mathrm{~mm}$ lat., lisos, glabros, múticos, con dos aristas apenas incipientes y con pelos antrorsos. Semilla péndula, 1,5 mm long., glabra y con pelos breves en el ápice.

Distribución geográfica: Conocida hasta ahora solamente para la localidad tipo.

Obs.1. Por sus raíces adventicias Sida vagans es afín a $S$. repens Cav., de Ecuador y Perú, de la que se diferencia por sus mericarpos múticos en oposición a los de $S$. repens con aristas tan largas como los mericarpos.

Obs. 2. El ejemplar tipo está identificado como Sida gracillima Hassl., especie muy parecida pero que se diferencia de $S$. vagans por ser erecta y tener mericarpos reticulados y con aristas $1 \mathrm{~mm}$ long.

Etimología: El nombre vagans alude al carácter viajero que le dan sus ramas rastreras con raíces adventicias. 


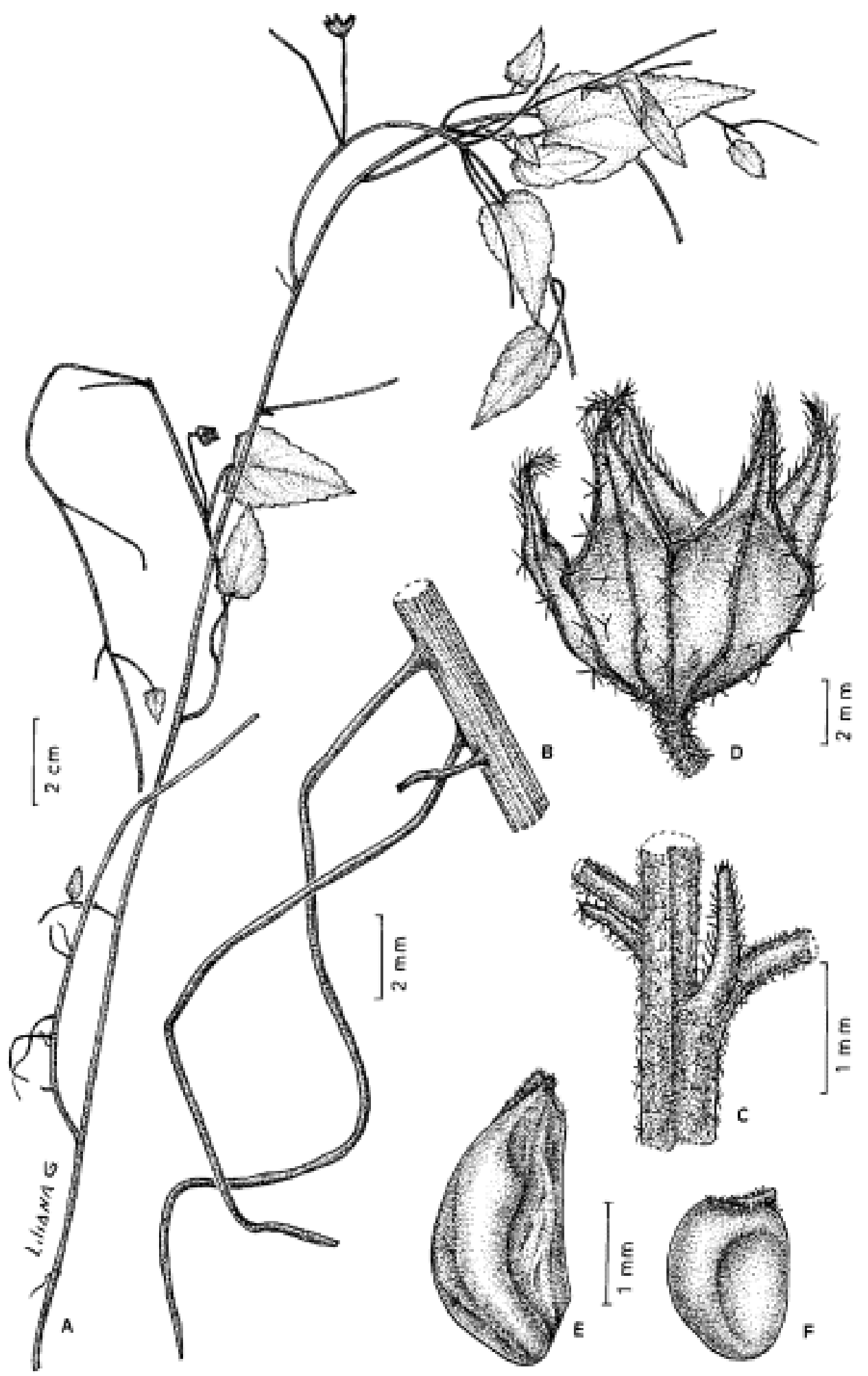

Fig. 7. Sida vagans. A: rama. B: tallo con raíces adventicias. C: tallo joven con estípulas. D: cáliz. E: mericarpo. F: semilla (A-F, Steinbach 2337). 


\section{Sida waltoniana Krapov., sp. nov.}

Fig. 8

Herba perennis basi lignescens caulibus procumbentes usque ad 2,50 m longis, eglandulosis, pilis $2 \mathrm{~mm}$ longis, hispidis vel glabrescens. Folia ovata longe acuminata basi cordata. Inflorescentiis axillaribus et terminalibus congestis; floribus sessilibus. Calyx 8-12 mm longis. Carpidiis 5 trigonis 2,5 $\mathrm{mm}$ longis, $1 \mathrm{~mm}$ latis, muticis vel submuticis.

Typus: Brasil. Goiás: entre Niquelandia y Macedo, en mato, 11-IV-1961, W. C. Gregory, A. Krapovickas \& J. Pietrarelli 10229 (holotypus CTES, isotypi LIL, UB).

Subarbusto erecto. Tallo con pelos estrellados de 3-4 ramas de $1 \mathrm{~mm}$ long. y setas $2 \mathrm{~mm}$ long. Estípulas lineares con pelos simples 1-2 mm long. Pecíolo 1-3 cm long., con indumento similar al del tallo. Lámina ovada, acorazonada, ápice agudo y margen crenado-aserrado; ambas caras con pelos estrellados de 2-4 ramas de 0,5-1 mm long., que dejan ver la epidermis. Flores solitarias, axilares o en panículas terminales casi áfilas. Pedicelos 20$35 \mathrm{~mm}$ long., articulados en el tercio superior, con pelos simples, 0,2-0,5 mm long. Cáliz 5 mm long., lóbulos triangulares $3 \mathrm{~mm}$ long. x 3 mm lat., margen de los lóbulos verde más oscuro; nervios principales y margen de los lóbulos con pelos estrellados de 2-4 ramas y setas ca. $1 \mathrm{~mm}$ long. Corola amarilla; pétalos $8 \mathrm{~mm}$ long., uña con pelos. Tubo estaminal 1,5 mm long., con pelos simples y estrellados. Carpelos 5. Mericarpos trígonos, 2,5 mm long. x 1,5 mm lat., múticos, cara dorsal lisa, caras laterales levemente reticuladas, frágiles, con pocos pelos en la línea de dehiscencia apical.

Distribución geográfica: Conocida solamente de la localidad tipo. Macedo se encuentra a $15 \mathrm{~km}$ al norte de Niquelandia.

Etimología: Dedico esta especie a la memoria de Walton C. Gregory, compañero de colección del tipo.

\section{Nota sobre Sida glabra}

Sida glabra Miller, 1768.

Sida arguta Swartz, Prodr.: 101. 1788. Typus:

"Mill. dict. Jamaica”. Swartz, Fl. Ind. occid. 2(2): 1205. 1800 [cita expresamente S. glabra Mill. como sinónimo]. Nombre superfluo para S. glabra Mill. (Fawcett \& Rendle, 1926, Fl. Jamaica 5: 113) [non Presl, 1835].

Sida ulmifolia Cav., Diss. 1: 15, tab. 2 fig. 4. 1785. Typus: "Insula S. Dom. V.S. communicatum a D. Thouin” (holotypus MPU!) [non Miller, 1768; nec Retz, 1783].

Sida truncata L'Her., Stirp. 1: 107-108, tab. 51. 1789. "Semina missa ex Hispaniola" [non Cav., 1785].

Sida gracilis L.C. Rich., Actes Soc. Hist. Nat. Paris 1: 111. 1792. Typus: in campestribus, in fruticosis Sa. Crucis 8bri - 9bri (holotypus P!) [non Elliott, 1822].

Sida emarginata Willd., Sp. pl. 3: 757. 1800. Nuevo nombre para $S$. truncata L'Her.

Sida Swartzii Dietr., Synops. 4: 487. 1847. Nuevo nombre para S. arguta Swartz

Sida glabra Mill. es un nombre aplicado a varias entidades, lo cual lleva a darle una amplitud que provoca confusión. Ver por ejemplo la larga lista de sinónimos que se le adjudican (Fryxell, 1985).

El tipo de Sida glabra (BM!) tiene el tallo casi glabro, la planta no tiene pelos glandulares ni tampoco los pelos simples largos, presentes en muchas de las especies de esta sección. Las hojas ovales de base acorazonada y ápice agudo ubican a esta especie en la sección Nelavaga, el haz presenta pelos simples y bifurcados muy pequeños, esparcidos. Las flores solitarias con pedicelos más largos que los pecíolos, en la axila presentan una pequeña rama florífera.

Obs. Sida arguta Swartz es un nuevo nombre para S. glabra (Fawcett \& Rendle 1926 5: 113). En el protólogo Swartz (1788) cita a Miller y aunque no menciona el epíteto "glabra" la diagnosis es copia fiel de la de Miller. Más tarde (Swartz, 1800: 1205) cita expresamente a $S$. glabra Mill. como sinónimo de $S$. arguta. 


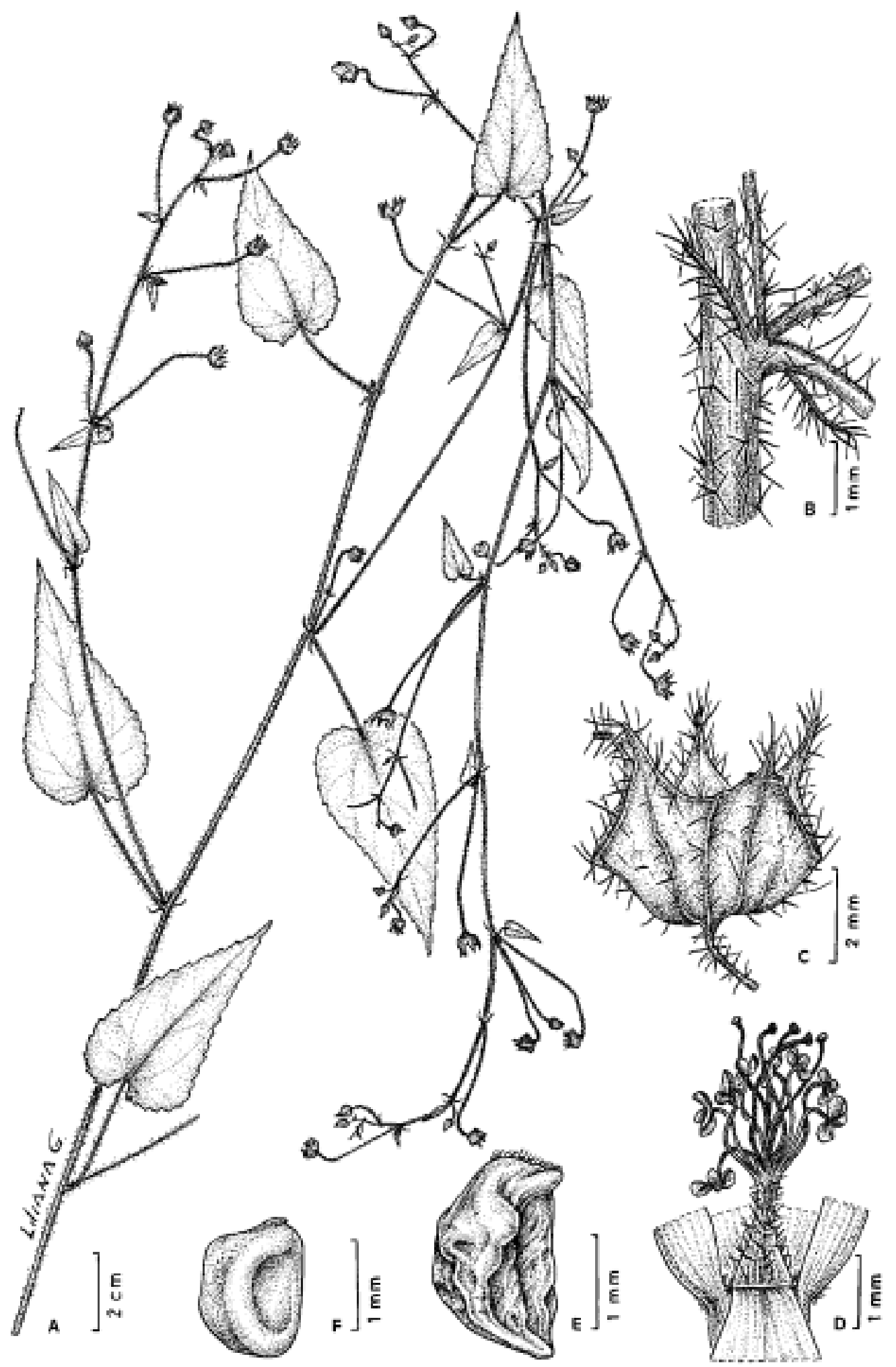

Fig. 8. Sida Waltoniana. A: rama. B: estípulas. C: cáliz. D: tubo estaminal. E: mericarpo. F: semilla (A-F, Gregory \& al. 10229). 


\section{Agradecimientos}

Deseo expresar mi agradecimiento a Liliana Gómez por las ilustraciones que acompañan este texto.

\section{Bibliografía}

BORSSUM WAALKES, J. van. 1966. Malesian Malvaceae revised. Blumea 14 (1):1-251.

FERNÁNDEZ, A. 1974. Recuentos cromosómicos en Malváceas. Bol. Soc. Argent. Bot. 15: 403-410.

—. 1981. Recuentos cromosómicos en Malvales. Bonplandia 5 (10): 63-71.

- A. KRAPOVICKAS, G. LAVIA \& G. SEIJO, 2003. Cromosomas de Malváceas. Bonplandia 12 (1-4): 141-145.

FRYXELL, P.A. 1985. Sidus Sidarum-V. The North and Central American species of Sida. Sida 11(1): 6291.

- 1987. Sidus Sidarum VI.- The Sida martiana (Malvaceae) complex in México. Sida 12 (1): 1321.

1988. Malvaceae of Mexico. Syst. Bot. Monogr. 25, 522 p.p.

- 1992. Malvaceae. In G. Harling \& L. Andersson, Flora of Ecuador 118: 1-141.

FUERTES AGUILAR, F.J. 1995. Sida L. (Malvaceae). In S. Diaz Piedrahita \& al. (eds.), Flora de Colombia 17: 1-142.

GANDOGER, M. 1924. Le genre Sida (Malvacée). Bull. Soc. Bot. France 71: 627-633.

GARILLETI, R. 1993. Herbarium cavanillesianum. Fontqueria 38: 3-248.

HAUMAN, L. 1963. Malvaceae en Flore du Congo, du Rwanda et du Burundi, 10: 92-190.

HOCHREUTINER, B.P.G. 1916. Monographia generis Anodae. Annuaire Conserv. Jard. Bot. Genève 20: 29-68.

KRAPOVICKAS, A. 1957. Números cromosómicos de Malváceas americanas de la tribu Malveae. Revista Agron. Noroeste Argent. 2(2): 245-260.

—_ 1969. Notas citotaxonómicas sobre Malváceas. Bonplandia 3(2): 9-24.

MACBRIDE, J.F. 1956. Malvaceae, Flora of Perú. Field Mus. Nat. Hist., Bot. Ser. 13, part IIIA, n. 2: 442593.

MEEUSE, A.D.J. 1961, Sida L. In A.W. Exell \& H.
Wild, Flora Zambesiaca 1(2): 475-484.

MERRILL, E.D. 1921. A review of the new species of plants proposed by N.L. Burman in his Flora Indica. Philipp. J. Sci. 19: 329.

RHEEDE, H. van. 1690. Hortus indicus malabaricus 10: 137, tab. 69.

RODRIGO, A. del P. 1944. Las especies argentinas y uruguayas del género Sida (Malvaceae). Revista Mus. La Plata, Secc. Bot. 6: 81-212.

SIVARAJAN, V.V. \& A.K. PRADEEP. 1996. Malvaceae of Southern Peninsular India. Daya Publishing House, Delhi.

SKOVSTED, A. 1935. Chromosome numbers in the Malvaceae. J. Genet. 31: 263-296.

STAFLEU, F.A. \& R.S. COWAN. 1976. Taxonomic Literature 1: 910, Gandoger.

—. 1986. Taxonomic Literature, 6: 297-299, Thouin.

UGBOROGHO, R.E. 1975. In A. Löve, IOPB Chromosome number reports, Taxon 24 (5/6): 671.

\section{Índice de nombres científicos}

Anoda Cav. 23

Anoda decumbens (A.St.-Hil. \& Naudin) Hochr. 22

Callirhoe papaver (Cav.) A. Gray 32

Krapovickasia 23

Lamarkia Medik. 8

L. morifolia (Cav) Medik. 8

Melochia cordata Burm.f. 8

Nela Vaga Rheede 5, 6

Physalastrum stoloniferum (Salzm. ex Turcz.) Monteiro 22

Sida L.

secc. Physalodes Griseb. 23

secc. Nelavaga 5, 7, 8, 11, 23, 39

alamosana S.Wats. 7

anodifolia Fryxell 7

arguta Swartz 39

Beddomei Jacob 7

Cabreriana Krapov. 7, 8, 10, 13, 14

caudata A.St.-Hil. \& Naudin 7, 8, 11, 14, 15

cearensis Ulbr. 7, 8, 9, 11, 15

chacoensis Hassl. 17

chapadensis K.Schum. 7, 8, 10, 15

cordata (Burm.f.) Borss.Waalk. 5, 7, 8

decumbens A.St.-Hil. \& Naudin 22

dictyocarpa Griseb. ex K.Schum. 7, 8, 10, 11, 12, 14, 16

elongata Blume 5, 7 
emarginata Willd. 39

Emilei Hochr. 7, 8, 9, 10, 11, 17

Endlicheriana C.Presl 20

esperanzae R.E.Fr. 7, 8, 10, 11, 12, 14, 18

Eugeniae Fuertes 7

fasciculata Willd. ex Spreng. 20

glandiflora (Paxton) Walp. 32

glabra Mill. 7, 39

glutinosa Comm. ex Cav. 5, 7, 9, 11, 19, 20, 21

glutinosa var. longearistata Monteiro 18

goyazensis K.Schum. 7, 8, 9, 11, 21

gracilipes Rusby 7, 9, 11, 21

gracilis L.C. Rich. 39

gracillima Hassl. 8, 9, 11, 22, 37

hederifolia Cav. 7

insperata Standl. \& L. Williams 20

javensis Cav. 5

Jussieana DC. 7, 8, 22, 23

laciniata Bovini 7, 8, 23

longepilosa Gand. 21

Luschnathiana Steud. 5, 7, 9, 11, 24

margaritensis Hassl. 25, 26

Martiana A.St.-Hil. 7, 8, 9, 11, 24, 25

Martiana var. viscosissima A.St.-Hil. 24

melanocaulon Hassl. 25

michoacana Fryxell 7

monticola Fryxell 7

mysorensis Wight \& Arn. 5, 7, 20

nemorensis Mart. ex Colla 7, 8, 11, 15, 25

nervosa DC. 20

nesogena I.M.Johnst. 7

piauhyensis Ulbr. 20

pindapoyensis Krapov. 7, 8, 9, 27, 28

pseudo-urens Baker f. 27

racemosa Burm. 20

radicans Cav. 8

repens Cav. 7, 37

rufescens A.St.-Hil. 7, 8, 11, 27

rupicola Hassl. 7, 8, 10, 11, 29

rupicola var. grandiflora Hassl. 29

Schininii Krapov. 5, 7, 9, 30, 31

Schumanniana Krapov. 7, 8, 32, 33

stolonifera Salzm. ex Turcz. 22

Swartzii Dietr. 39

tomentella Miq. 14, 15

tomentella var. brevicalyx K.Schum. 15, 25

truncata L'Her. 39

ulmifolia Cav. 39

urens L. 7, 8, 11, 34, 37

urens microsp. S. boliviana Gand. 37

urens var. aurea Hassl. 27 urens var. aurea $\mathrm{f}$. Warmingiana Monteiro 27

urens var. grandiflora K.Schum. 32

urens var. rufescens (A.St.-Hil.) Baker f. 27

vagans Krapov. 7, 9, 37, 38

veronicifolia Lam. 7

verticillata Cav. 34

viscidula Klotzsch 24

Waltoniana Krapov. 7, 8, 9, 39, 40

Willdenowii D.Dietr. 20

Xavieri Monteiro 24

hirta urticata \& c. P. Browne 34

\section{Índice de coleccionistas}

Ahumada, O. 3640 (22), 4521 (1), 4788 (7), 8880

(7)

Ahumada, O. \& A. Rotman 4349 (1)

Antezana, C. 579 (10), 1149 (10), 1209 (10), 1220

(10), 1223 (10)

Arbo, M. M. \& al. 742 (22), 3985 (2), 4009 (15),

4239 (15), 4473 (14), 4951 (15)

Aymard, G. 3438 (12)

Balansa, B. 1630 (6), 4381 (6), 4382 (18)

Bang, M. 1146 (10)

Beck, S. G. 741 (7), 907 (10), 22449 (7), 6504

(18), 7986 (19), 11650 (1), 17743 (21), 19860

(22), 22449 (7)

Beck, S. G. \& al. 11472 (1)

Benítez, B. 164 (22)

Bertero, C. G. L. s.n. (8)

Berti, H \& M. Escalante 504 (22)

Biurrum, F. 646 (5), 1312 (5), 1318 (7), 3027 (5), 3033 (7), 3276 (7), 3394 (7), 4387 (7), 5068 (7), 6449 (5)

Blanchoud, G. 2088 (22)

Bordon, A. O. 64 (7)

Borsini, O. 570 (22), 582 (21)

Botelho, M. B. 10 (22)

Brescia, C. \& E.H. Marchesi 5061 (22)

Brizuela, J. 922 (5)

Browne, P. s.n. (22)

Bueno, O.L. 257 (22), 649 (22), 3016 (22)

Bueno, O.L. \& A. Krapovickas 3621 (22)

Burkart, A. 25993 (5)

Caballero, R. HR-38 (10)

Cabrera, A. L. 4063 (12), 15818 (1), 34106 (1)

Cabrera, A. L. \& al. 27949 (22), 33871 (1)

Cabrera, A. L. \& H. A. Fabris, 22684 (1)

Cabrera, A. L. \& M. M. Gutiérrez, 33621 (1) 
Carauta, J. P. P. 907 (2), 3782 (16), 4826 (21)

Cárdenas, M. 4790 (10)

Carneiro, J. 1099 (22)

Carnevali, R. 4274 (16)

Castellanos, A. 3200 (5)

Charpin, A. \& L. Ramella 21666 (6)

Clausen, P. 126 (2)

Commerson P. s.n. (8), s.n. (22)

Constance, L. \& O. Tovar 2325 (22)

Cordeiro, J. 44 (22)

Cuezzo, A. R. 1098 (5), 11748 (22)

Degen, R. 1994 (18)

Del Vitto, L. A. \& al. 5101 (7)

Dematteis, M. 638 (22)

Duarte, A. 6091 (14)

Ducke, A. 1332 (3)

Eiten, G. \& L.T. Eiten 4101 (12), 4459B (8)

Fernandes, A. 1435 (8)

Ferreyra, R. 9350 (21), 19300 (21)

Ferrucci, M. S. \& al. 1724 (21), 2047 (22), 2077 (21)

Fiebrig, K. 1470 (6), 1418a (6), 4137 (6), 5173 (11)

Figueiredo, M. A. 585 (12)

Fortunato, R. 2714 (22), 6594 (5)

Fortunato \& al. 3082 (1), 3676 (1)

Fries, R.E. 540 (7)

Fróes, R.L., 27056 (3)

Fryxell, P. A. \& E. J. Lott 3312 (12)

Fuentes, A. \& G. Navarro 2596 (1)

Galander, C. s.n. (5)

Galantón, N. 62 (12)

Gerold, 146 (10)

Glaziou, A. 3872 (2)

G Pedra do Cavalo 689 (3)

Gottsberger, G. 12-10368 (22), 14-28568 (14)

Gregory, W. C., A. Krapovickas \& J. R. Pietrarelli 9608 (22), 9802 (18), 9988 (19), 10118 (18), 10140 (14), 10151 (14), 10229 (24), 10231 (14), 10238 (12), 10308 (18), 10445 (9), 10482 (14), 10501 (18), 10505 (8), 10553 (18)

Guaglianone, E. R. \& al. 2524 (1), 2725 (21)

Gutiérrez, E. \& al. 1542 (10)

Gutiérrez, J. 331 (5)

Haene, E. H. 434 (7), 565 (5)

Hagelund, K. 9263D (22)

Hahn, W. 1573 (19)

Hassler, E. 10294 (16), 10540 (21), 10990 (19), 11037 (18), 11041 (19), 11065 (16)

Hatschbach, G. 11822 (22), 12514 (2), 12609
(22), 16052 (2), 19861 (22), 21839 (14), 24156 (22), 24861 (16), 29309 (16), 31865 (14), 43835 (16), 43862 (14), 47582 (16)

Hatschbach, G. \& al. 59027 (19), 61768 (14), 62428 (16), 64632 (14), 64645 (14), 70809 (9), 70841 (9), 70965 (14), 71038 (14), 71303 (14), 72975 (22), 73068 (19), 75007 (14)

Hatschbach, G. \& A. Lourteig 41041 (19)

Hensold, N. \& al. s. n. SPF 22402 (15)

Heringer, E. P. 5658 (2), 6388 (16), 6410 (22), 6411 (8), 9349 (14), 10363 (14), 11442 (14), 11505 (8), 14662 (14)

Heringer, E. P. \& al. 4870 (16), 11418 (16)

Herrera, J. 361 (22)

Hoehne, W. s.n. (2)

Holst B. \& al. 4921 (1)

Honfi, A. I. 61 (22)

Humboldt, F. von \& A. J. A. Bonpland s.n. (8)

Hunziker, A.T. 12103 (5), 12201 (7), 13472 (5), 14696 (7), 17420 (5), 24348 (1)

Hunziker, A. T. \& E. Di Fulvio, 17006 (7), 16932 (7)

Ibarrola, T. 3390 (22), 4292 (22)

Infantes Vera, J. 4008 (21)

Insfrán, P. 1334 (22)

Irwin, H.S. \& al. 17587 (16), 17683 (22) 31797 (18)

Irwin, H.S. \& T.R. Soderstrom 5521 (12)

Jard. Bot. de B. Hor. 7948 (18)

Joly, C. A. 17335 (22)

Jussieu, J. de, P-JU 12267 (12)

Keller, H. 160 (16), 658 (22)

Kiesling, R. 3026 (7)

Klein, R.M. 8218 (22)

Koch, S.D. \& P.A. Fryxell 83260 (12)

Kranz, W. 346 (22)

Krapovickas, A. 1556 (7), 3504 (1), 3512 (1), 3513 (22), 4779 (7), 6701 (1); 6976 (19), 7933 (17), 7935 (17), 7973 (5); 7982 (12); 7992 (22), 8248 (22), 8289 (8); 9424 (20), 10011 (6), 10030 (22), 10505 (8); 12940 (12)

Krapovickas, A. \& al. 14228 (6), 14243 (22), 15559 (8); 18602 (7), 18632 (7), 19016 (1), 19020 (1), 19025 (22), 19064 (7), 19166 (1), 19246 (1), 19128 (1), 19198 (1), 19132 (1), 19246 (1), 19283 (7), 19342 (1), 19348 (7), 19414 (1), 19420 (1), 19421 (12), 19456 (22), 19457 (12), 19461 (1), 19475 (1), 22104 (1), 22970 (22), 24336 (22), 26474 (19), 26575 (1), 27859 (1), 28011 (7), 28014 (1), 28259A (1), 28259B (1); 28462 (22), 28464 (22), 
28494 (22), 28505 (1), 28973 (22), 37424 (1), 37906 (19), 38699 (18), 38770 (12), 38828 (8), 38829 (16), 40107 (18), 40152 (14), 40160 (22), 45400 (7), 45495 (7), 47267 (12), 47365 (22), 47394 (1), 47417 (1), 47434 (1), 47436 (1), 47473 (1); 47892 (22)

Krapovickas, A. \& C.L.Cristóbal 11271 (1), 11388 (19), 11416 (22), 11460 (22), 11664 (22), 11808 (22), 12731 (22), 14515 (7), 14517 (1), 14543 (7), 14808 (22), 17302 (5), 17320 (5), 17542 (5), 20718 (7), 23501 (12), 24528 (7), 26719 (7), 27936 (5), 27937 (7), 27940 (7), 28197 (1),35398 (2), 35450 (22), 39388 (16), 43760 (22), 44182 (19), 44336 (7), 44380 (1), 44508 (22), 44740 (22), 44988 (22), 45112 (22), 46249 (7), 46405 (1), 46544 (1), 46555 (5), 46592 (5), 46597 (5), 46667 (22), 46709 (7), 46739 (7)

Krapovickas, A. \& R. Fortunato 43923 (16)

Krapovickas, A. \& P.R. Legname 4509 (21), 10769 (5)

Krapovickas, A. \& A. Schinini 30207 (1); 30575 (22), 30932 (5), 30933 (12), 30987 (22), 30988 (12), 31080 (7), 31081 (5), 31283 (5), 31351 (7), 31839 (18), 31979 (18), 32030 (19), 32031 (14), 32097 (22), 32098 (1), 32099 (20), 32250 (20), 32267 (20), 32483 (18), 32485 (1), 32628 (18), 32756 (22), 32787 (6), 32940 (14), 32950 (20), 34638 (1), 34986 (22), 35736 (1), 35868 (22), 36119 (1), 36163 (18), 36220 (19), 36221 (6), 36223 (20), 36363 (6), 36494 (6), 36497 (1), 36541 (6), 38646 (1), 38850 (12), 38851 (1), 39105 (7), 39201 (1), 39303 (7)

Krapovickas, A. \& G. Seijo 47663 (7), 47677 (7), 47741 (7)

Krukoff, B.A. 10020 (21), 10047 (21)

Kummrow, R. 475 (22)

Kurtz, F. 240 (18)

Lasseign, A. P21184 (22)

Legname P.R. \& al. 6909 (16), 8530 (19), 8786 (21)

Legname, P. R. \& A. R. Cuezzo 4028 (21), 4056 (7), 7044 (21), 7115 (21), 7474 (1), 7549 (7)

Liberman, M. \& al. 1932 (7)

Lima, A. 55-2401 (3)

Lombardi, J.A. 2811 (22)

Lorentz, P.G. 161 (5)

Lourteig, A. \& al. 2839 (22)

Luetzelburg, P. von, 23592 (12), 23738 (12)
Luna, F.E. 158 (7), 1438 (7)

Lurvey, E.L. 664 (22)

Luschnath, B. 10 (14)

Luteyn, J.L. \& L.J. Dorr 13512 (22)

Magnoni \& al. 31 (7)

Maranta, A. 421 (5), 691 (5)

Martius, C.F.P. von, s.n. (16)

Maruñak, V. 584 (1)

Mathews, A. 1552 (18)

Mattos Silva, L.A. 166 (22)

Melo, P.H.A. 826 (22)

Mereles, F. 6619 (6)

Meyer, T. \& Vaca 23354 (5)

Michel, R. Ch. de \& al. 406 (12)

Molina.A. \& A. Cabral 329 (7)

Montes, J.E. 227 (16); 1596 (22), 2413 (16), 14793 (22), 14929 (22), 15133 (16), 15425 (16), 15764 (16)

Moraes, M. 453 (21)

Morel, I. 939 (22), 7322 (22)

Morello, J. \& R.A. Cuezzo 60 (5), 388 (5), 1125 (7)

Nee, M. 38869 (21), 41483 (21)

Novara, L. 2724 (1), 9842 (7)

Novara, L. \& S. Bruno 9895 (22)

Ochioni, P. 571 (22)

Patridge, W. s.n. BAB 60068 (5)

Pedersen, T.M. 5311 (19), 8118 (16), 9029 (22), 10829 (5), 12896 (5), 13502 (22), 14628 (5)

Peredo, I. s.n. (1), 349 (6)

Pineschi, R.B. 244 (2)

Pinto, G. 50-25 (14)

Pire, S.M. \& al. 72 (22)

Pires, J.M. 58147 (12)

Pohl, J.E. 2850 (d.n.1312) (9)

Pott, A. 1634 (18), 3380 (22), 7930 (20)

Quarín C. \& al. 859 (16)

Quarín, C. \& A. Schinini 1014 (22)

Quintana \& al. 662 (1)

Ramella, L. 2200 (6)

Ratier de Colina 355 (1)

Regnell, A.F. I 16 (2), I 16 ex p. (16)

Renolfi, R.F. 281 (7)

Ribas, O.S. 1396 (22)

Riedel, L. s.n. (14), 1604 (4), 2328 (2)

Rizzo, J.A. \& A. Barbosa 1056 (9)

Roic, 600 (5)

Rojas, T. 1221 (19), 2591 (18), 3525 (19), 3630 (16), 13654 (6), 13654a (6)

Rosa 275 (5)

Saint-Hilaire, A. s.n. (14), s.n. (15), s.n. (18) 
Salino, A. \& J. R. Stehmann 3297 (13)

Salzmann, P. s.n. (12)

Sánchez, 6 (1)

Santos, E.B. 27 (22)

Santos, T.S. 1945 (14)

Saravia Toledo, C. 10697 (7), 10945 (22)

Saravia Toledo, C. \& al. 12954 (7)

Schinini, A. 4698b (6), 9049 (18), 10901 (16)

Schinini, A. \& al. 7136 (22), 17006 (16), 21863 (22), 27960 (22), 32651 (22), 36179 (22)

Schinini, A. \& E. Bordas 14859 (6), 15220 (5), 16604 (7), 17851 (6), 17852 (19), 20231 (21), 20633 (19)

Schinini, A. \& G.R. Caballero Marmori 27233 (22)

Schinini, A. \& R. Carnevali 23259 (22)

Schinini, A. \& G.A. Cuadrado 30339 (22)

Schinini, A. \& J.M.González 9303 (22)

Schinini, A \& R.N. Martínez Crovetto 12816 (16), $12884(22)$

Schinini, A. \& R. Palacios 25564 (5)

Schinini, A. \& R.O. Vanni 26020 (22)

Schulz, A.G. 556 (22), 837 (19), 841 (5), 2101 (22), 2202 (5), 5006 (12), 5514 (21), 6715 (5), 7804 (22), 10653 (5), 16976 (22), 17398 (5)

Schulz, A.G. \& Varela 5472 (21)

Schwarz, G.J. 8424 (22), 9568 (22), 10080 (22), 11659 (22)

Schwindt, E. 92 (22), 3243 (22), 4008 (22)

Seidel R. \& S.G. Beck 316 (22), 339 (1)

Seijo, G. \& al. 3226 (29)

Silva, J.M. \& al. 3041 (16)

Silverstone-Sopkin, P. \& al. 6064 (21), 7189 (21)
Smith, H.H. 718 (21)

Solis Neffa, G. \& al. 769 (5), 1070 (5)

Solomon, J.C. \& M. Nee 14297 (21)

Soria, N. 2251 (19), 4001 (18), 6484 (18)

Sota, A. de la, 3747 (7), 4575 (1)

Sota, A. de la, \& P.R. Legname 950 (5)

Sparre, B. \& F.Vervoorst 701 (6)

Spegazzini, C. s.n. (1)

Spichiger, R. \& al. 2590 (6)

Standley, P.C. 24639 (8)

Steinbach, J. s.n. (18), 1246 (21), 2337 (23)

Steyermark, J.A. \& V. Carreño Espinoza 108781 (21)

Terán, J. BN149 (10)

Tolaba, J. 2404 (1), 2419 (1), 2438 (1)

Tressens, S.G. \& al. 1774 (22), 2081 (22), 2829 (22)

Tressens, S.G. \& W. Barrett 5241 (22)

Tressens, S.G. \& H. Keller 6997 (22), 7003 (5)

Türpe, A.M. \& al. 4753 (22)

Ule, E. 7461 (8), 9065 (3)

Vanni, R.O. \& al. 2076 (1), 2536 (7), 2793 (16), 3395 (22), 3851 (22), 4344 (5)

Vargas C., C. 5196 (21)

Vargas, E. \& R. Seidel 451 (21)

Vauthier, 21 (12).

Villa Carenzo, M. 16 (5)

Widgren, J.F. 478 (2)

Woytowski, F. 34434 (21)

Willink, A. 26 (12), 110 (21), 194 (21)

Xavier, L. s. n. Laboratorio de Fibras 342 (14)

Zardini, E.M. 29894 (22), 31426 (22), 32441 (22), $38939(22)$

Original recibido el 12 de septiembre de 2005; aceptado el 8 de noviembre de 2005. 